\title{
A high resolution view of an adolescent flavivirus
}

Max Renner ${ }^{1 *}$, Wanwisa Dejnirattisai ${ }^{2 *}$, Loïc Carrique ${ }^{1}$, Itziar Serna Martin ${ }^{3}$, Dimple Karia ${ }^{1, \#,}$

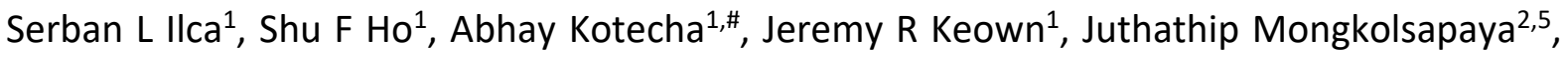
Gavin R. Screaton², Jonathan M. Grimes ${ }^{1,4}$

1. Division of Structural Biology, The Wellcome Centre for Human Genetics, University of Oxford, Oxford, UK

2. Nuffield Department of Medicine, The Wellcome Centre for Human Genetics, University of Oxford, Oxford, UK

3. Bijvoet Centre for Biomolecular Research, Department of Chemistry, Faculty of Science, Utrecht University, The Netherlands

4. Science Division, Diamond Light Source Ltd, Didcot, UK

5. Dengue Hemorrhagic Fever Research Unit, Office for Research and Development, Faculty of Medicine Siriraj Hospital, Mahidol University, Bangkok, Thailand

\#Current address: Materials and Structural Analysis Division, Thermo Fisher Scientific, Achtseweg Noord, Eindhoven, 5651 GG, Netherlands

*equal contributions

Corresponding authors. E-mail: juthathip.mongkolsapaya@well.ox.ac.uk;

gavin.screaton@medsci.ox.ac.uk; jonathan@strubi.ox.ac.uk 


\section{Abstract}

Mosquito-transmitted flaviviruses, such as Dengue virus (DENV) or Zika virus (ZIKV), are responsible for significant economic damage and human misery. In infected cells, flaviviruses first assemble into an immature form within the endoplasmatic reticulum (ER), and then undergo further processing by furin protease in the trans-Golgi. Despite substantial efforts, previous cryogenic electron microscopy (cryo-EM) studies of immature flaviviruses were restricted to low to medium resolutions, limiting our understanding of maturation. To better grasp the process of maturation, we have carried out cryo-EM reconstructions of immature Spondweni virus (SPOV), an emerging human flavivirus belonging to the same serogroup as ZIKV ( 75\% amino acid identity). By combining localized reconstruction and focused refinement, we were able to improve the resolution to $3.8 \AA$, yielding unprecedented insight into the immature form. The structure elucidates how, at neutral $\mathrm{pH}$, polar interactions conceal the furin recognition site within trimeric envelope (E) protein spikes. Furthermore, we identify how a strictly conserved $\mathrm{pH}$ sensor anchors the precursor membrane (prM) protein to immature E. We reconstructed mature forms of SPONV and DENV to $2.6 \AA$ and $3.1 \AA$, respectively. Comparison with immature virus shows a conserved binding pocket for a lipid headgroup, which forms as a consequence of the rearrangement of amphipathic stem-helices of E. We propose a structural role for the pocket and suggest it stabilizes mature E. Taken together, our data suggest a compelling rationale for low-pH triggered conformational rearrangement in the Golgi, which occurs during flavivirus maturation. 


\section{Main Text}

The genus Flavivirus contains many important mosquito-borne human pathogens, such as dengue virus (DENV) and Zika virus (ZIKV). Flaviviruses represent a significant economic and health-care burden to affected countries, particularly in Southeast Asia and South America ${ }^{1}$. The surface of mature, infectious flaviviruses is composed of an icosahedral shell of 90 flatlying envelope $(E)$ protein dimers ${ }^{2-4}$, the main target of humoral immunity ${ }^{5,6}$. E contains the fusion peptide, which is responsible for insertion into host membranes during infection?. Within infected host cells, progeny immature viruses bud into the lumen of the endoplasmatic reticulum (ER) and follow the secretory pathway through the Golgi apparatus ${ }^{3}$. In contrast to their mature counterparts, immature virions possess 60 protruding spike-like trimers of precursor membrane $(\mathrm{prM})-\mathrm{E}$ complexes $\left(\mathrm{prM}_{3} \mathrm{E}_{3}\right)^{8,9}$. The $\mathrm{pr}$ domain of prM binds to $E$, obscuring the fusion peptide and thereby preventing unproductive fusion within the already infected cell ${ }^{10}$. The $\mathrm{M}$ domain of prM is embedded in the membrane and connected to pr via a linear linker region. When immature virions reach the low-pH environment of the transGolgi network (TGN), the trimeric $\operatorname{prM}_{3} \mathrm{E}_{3}$ spikes rearrange into the flat-lying conformation, characteristic of the mature virus ${ }^{11,12}$. The TGN-resident protease furin ${ }^{13}$ then cleaves a recognition site between pr and $M$. pr remains associated with $E$, inhibiting its fusion function, until the virus is transported outside of the cell. There, the neutral $\mathrm{pH}$ environment triggers the dissociation of $E$ and $p r$, rendering the virus infectious ${ }^{11}$.

Structural studies of immature flaviviruses via cryogenic electron microscopy (cryo-EM) have

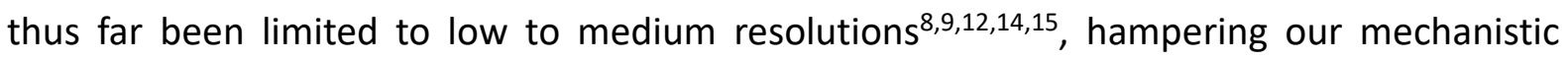
understanding of the maturation process. Here we investigated flavivirus maturation by high resolution cryo-EM. We chose to carry out this study using Spondweni virus (SPOV) ${ }^{16}$, a human flavivirus that is closely related to ZIKV ( $75 \%$ amino acid identity) and has remained structurally uncharacterised until now. Due to their similarity, SPOV was initially misclassified as a strain of ZIKV in neutralization tests ${ }^{17,18}$. SPOV was identified in Sub-Saharan Africa, but has recently been detected in Culex quinquefasciatus mosquitoes in Haiti, indicating that the virus may be adapting to vectors that prefer human hosts and that the epidemiology may therefore be changing ${ }^{19,20}$. In addition, mutual infection enhancement between DENV, ZIKV, and SPOV by immune sera has been demonstrated in cell culture ${ }^{21}$. We have used localized 
reconstruction ${ }^{22}$ and focused refinement to obtain a $3.8 \AA$ resolution cryo-EM structure, providing unprecedented insights into the immature form. For comparison, we have also

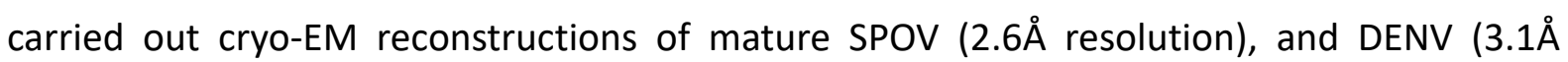
resolution). Our data shows how the furin recognition site on pr is concealed in the trimeric spike and how prM is anchored to $\mathrm{E}$ via a strictly conserved and mutation-sensitive histidine. Comparison with mature virus reveals that rearrangement of amphipathic helices in E leads to the formation of a binding pocket for a lipid headgroup. We propose the lipid stabilizes the conformation of membrane associated helices of $E$ and the binding site may be a potential target for the development of antiviral compounds. Based on our structures we suggest a function for the immature trimeric state of flavivirus glycoproteins, and a pathway for glycoprotein rearrangement during maturation.

\section{Polar interactions fix the Furin cleavage sites within immature trimers}

To facilitate collection of high-quality cryo-EM data outside of biosafety containment, we developed an optimised UV-exposure protocol that completely inactivates virus, while fully maintaining sample integrity (Extended Data Fig. 1a and b). Our samples contained a mixture of mature and immature particles (Extended Data Fig. 1b, black and white arrows, respectively). By only selecting immature particles we were able to obtain a reconstruction at 7.8Å resolution (Fig. 1a, b and Extended Data Table 1). The map shows the overall architecture of the spike-like trimers and extended areas of exposed membrane around the 3-fold and 5fold vertices. The virion possesses a diameter of $560 \AA$, comparable to that of ZIKV and DENV 8,9 .

At $7.8 \AA$ resolution, the interpretability of a map is limited. We used localized reconstruction ${ }^{22}$ and focused refinement to provide high resolution insight into prM-E complexes (Extended Data Fig. 2). We obtained a $4.2 \AA$ resolution map of the $\operatorname{prM}_{3} E_{3}$ trimer (Extended Data Fig. 3) and $3.8 \AA$ resolution for monomeric $\mathrm{prM}_{1} \mathrm{E}_{1}$ composing the trimeric spikes (Fig. 1c, $d$ and Supplementary Video 1). In the structure, the pr domain sits on top of the E protein, covering the fusion loop and burying a combined total surface area of $\sim 3100 \AA^{2}$. Within the context of the spike, three copies of $\mathrm{prM}_{1} \mathrm{E}_{1}$ form an asymmetric trimer (i.e. not following C3-symmetry), in which the three pr domains sitting at the tips of E come together and interact (Fig. 1d and 
Extended Data Figure 4). The RSRR furin recognition motif, which is critical for maturation, is found towards the end of the pr-domain (Fig. 1C, e). Polar interactions between E residues (in particular Glu62 and Glu245) and positively charged residues on pr fix the position of the furin site (Fig. 1e). Furthermore, hydrophobic prM residues (Ile96 and Leu98) directly downstream of the furin site, bury into the surface of $E$, providing additional stabilization. In the context of the trimer, the furin site is inaccessible (Fig. 1d).

\section{A pH-sensing conserved histidine anchors the pr-drawstring}

A central question in flavivirus maturation is how low $\mathrm{pH}$ in the trans-Golgi induces the necessary conformational rearrangements in the $\operatorname{prM}_{3} \mathrm{E}_{3}$ spike, that lead to exposure of the furin site on pr. E and prM are anchored in the viral membrane via their respective membrane associated regions. In $E$ these encompass two amphipathic (which lie flat on the membrane) and two transmembrane (TM) helices (Fig. 1d), while M possesses one amphipathic and two TM-helices (Fig. 2a). The pr domain of prM connects to the membrane-associated M domain via a long, linear linker. We do not observe map density for residues 102 to 119 of the pr-M linker, likely due to a high level of flexibility (Fig. 2a, dotted line). This disordered region spans a distance of roughly $55 \AA$, which can be covered by 17 residues in an extended conformation. The last clearly visible residue prior to this flexible region is a histidine (His101), which is buried in a pocket on E lined with hydrophobic residues (Fig. 2b).

The linker is anchored at this position on one side and at the $M$ region on the other side, reminiscent of how a bowstring is held by the limb tips of a bow. While the prM sequence is relatively diverse compared to that of $\mathrm{E}$, His101 is highly conserved (Fig. 2c). A decrease in $\mathrm{pH}$ would lead to protonation of His101, destabilizing the prM-E interaction. These structural data are underlined by previous functional studies which identified the equivalent histidines in Japanese Encephalitis virus (JEV) ${ }^{23}$ and $\mathrm{DENV}^{24}$ to be important for the low-pH induced dissociation of prM and E. One study showed that mutation of the histidine to alanine inhibited processing of $\mathrm{prM}^{24}$. The mutant could be rescued by a charge-inversion (Glu to Lys mutation) of an E protein residue, which in our structure is responsible for sequestering the furin site (Glu62 in Fig. 1e). Thus, destabilization of the upstream furin site could counteract 
mutation of the $\mathrm{pH}$-switch. These data support His101, and the equivalent histidines in other flaviviruses, as important $\mathrm{pH}$ sensors during maturation and to anchor the pr-M linker.

\section{E engages the pr domain via a flexible hairpin}

From the same dataset, we solved the structure of the mature form of SPOV (which lacks the pr domain), allowing us to examine which changes occur during maturation. We selected mature particles and reconstructed a map to $2.6 \AA ̊$ resolution (Fig. 3a and Extended Data Fig. 5). The virion has a smooth appearance, typical for members of the genus Flavivirus, with a diameter of $\sim 460 \AA \AA$. The $E$ proteins on the surface are arranged as antiparallel dimers (Fig. 3b), forming a tight cage that almost entirely covers the lipid bilayer. Unlike DENV (which is also glycosylated at Asn67), SPOV E possesses only a single glycosylation site at position Asn154 (Fig. 3b, c). The density indicated core fucosylation at the first GIcNAc, which is consistent with previous studies showing that fucosylation is present at the Asn153-glycan (DENV numbering) but not the Asn67-glycan for all DENV serotypes ${ }^{25}$. In ZIKV, the Asn154-glycan has been shown to be important for pathogenicity ${ }^{26}$, and for oral infectivity in Aedes aegypti mosquitoes ${ }^{27}$. The lipid membrane shows a kinked morphology and bilayer thinning ${ }^{28}$, induced by the membrane-associated helices of the embedded proteins (Extended Data Fig. 5a).

We then assessed the conformational changes within the ectodomain of $E$ in presence and absence of the pr domain. Despite the dramatically differing overall morphologies of mature and immature virions, the conformations of the E ectodomains are remarkably similar in both states. We do observe a downward hinge movement of roughly $15^{\circ}$ in mature $E$ (Extended Data Fig. $5 c$ ). Such hinge movements are typical of $E$ proteins and have been observed throughout its various structural states described in the literature ${ }^{29}$. We also find that a $\beta$ hairpin (residues 244-257) of E, located at the interface to the pr domain, shifts its position in the immature virus to optimally bind the pr domain (Fig. 3d, immature $E$ hairpin in grey). Specifically, polar interactions between the E hairpin and Asp64/Asp66/Asp40 of pr stabilize binding of the pr domain to $\mathrm{E}$. His 250 is clearly visible at the interface, and deprotonation of this conserved residue in DENV has been suggested to be involved in dissociation of cleaved pr at neutral $\mathrm{pH}^{30}$. 


\section{Rearrangement of amphipathic helices leads to formation of a lipid binding}

\section{pocket}

While the domain architecture of $E$ remains constant, there is a significant reorganization of membrane associated helices of E, going from the immature to the mature form (Fig. 4a, b). In mature $\mathrm{E}$ the amphipathic helix $\mathrm{H} 2$ is splayed away from the transmembrane bundle of TM1 and $\mathrm{TM} 2$, while amphipathic helix $\mathrm{H} 1$ has reoriented by almost $180^{\circ}$, relative to the helix bundle (Fig. 4b). The position of the membrane associated helices has also shifted relative to the ectodomain of E (Extended Data Fig. 5c). Notably, while TM and amphipathic helices are tightly packed together in the immature virus, the reorganization has left a pocket-like gap in between the helices in mature SPOV. We examined the EM map in the vicinity of the pocket and found that it is occupied by strong density resembling the headgroup of a phosphatidylethanolamine lipid (PE), with partially resolved fatty acid tails (Fig 4b, c). PE is the most abundant phospholipid in the lipidome of Aedes aegypti and Aedes albopictus cells ${ }^{31}$. The PE fills the pocket between the membrane associated helices of mature $E$, thereby keeping them at a fixed distance and position. Hydrophobic residues surround the pocket (Phe454, Leu499) and a histidine (His447) is found packing against the lipid, in close vicinity to the phosphate group of PE (Fig. 4b). Multiple sequence alignment of flavivirus E sequences reveals that the histidine adjacent to the pocket is conserved across all analysed sequences (Fig. 4d).

Considering the conservation, we wanted to assess if a lipid is present in related pathogenic flaviviruses, such as ZIKV or DENV. We inspected the density in this region in the deposited

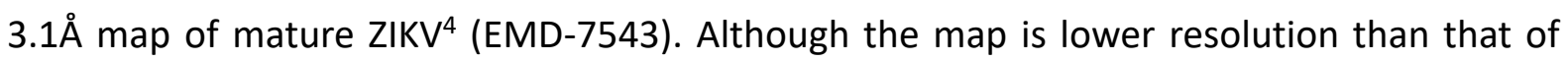
SPOV, we can observe prominent density in the identical position (Fig. 4e). Similarly, we examined the previously solved cryo-EM structure of DENV2 ${ }^{2}$. Because the available $3.6 \AA$ resolution map was not quite clear and resolved well enough to unambiguously determine the presence of a lipid, we carried out our own cryo-EM reconstruction of DENV2 (Extended Data Fig. 6). The reconstruction reached a resolution of $3.1 \AA$ and again revealed a lipid in the same region (Fig. 4f), suggesting that the binding pocket is conserved in flaviviruses. Notably, a functionally equivalent observation has recently been made in Sindbis alphavirus, where a lipid pocket factor was found buttressed in between the membrane associated helices of the 
glycoproteins $^{32}$ (Fig. 4g). A histidine was also found packing against the pocket factor in this case, and has been suggested to be protonated at low $\mathrm{pH}$ during virus entry and to be involved in subsequent collapse of the lipid-binding pocket ${ }^{32}$.

To further investigate the role of the conserved residues adjacent to the lipid, we constructed mutant viruses via Gibson assembly ${ }^{33}$ and assessed their growth. We chose to carry out mutagenesis in DENV2, as this is the more amenable system and impactful pathogen. We found that no virus could be recovered after exchange of His437 (equivalent to His447 in SPOV, Fig. 4b) to either a negatively charged glutamate or a small and neutral alanine (Fig. 4h). Similarly, we observed no virus recovery upon introducing a bulky Tyr sidechain at position Gly441 (Gly451 in SPOV). This glycine is in close contact with the lipid and any other amino acid besides Gly would sterically displace the lipid, which may explain why it is strictly conserved at this position (Fig. 4d). Although we cannot exclude with absolute certainty that these mutations interfere with the folding of $E$, the results suggest that an intact lipid binding pocket is important in the virus lifecycle, with a specific role for the adjacent histidine.

\section{Implications for flaviviral maturation and therapeutic intervention}

A remarkable reorganization of the flavivirus protein shell occurs during maturation and, with no intermediate structures available, the trajectory of this process remains undetermined. Previously, it has been speculated that large scale rotations of the E ectodomains might be involved in reorienting immature glycoproteins into their mature positions. It has been argued that in the course of this process the pr-M linker acts as a 'drawstring' and pulls on the ectodomains, thereby rotating them. However, simultaneous pivoting of multiple ectodomains in neighbouring asymmetric units of the virion is, in our view, sterically problematic and the energetic driver of the pulling motion is unclear. Instead, we anticipate that simple glycoprotein translations in the fluid lipid bilayer impose a much lower energy barrier and are sterically feasible. We propose that translations of glycoproteins in the immature-mature transition make use of the available space in the membrane at the 5- and 3-fold vertices (Fig. 1a) to reposition the proteins. Indeed, such translational fluctuations may explain the difficulties in achieving high resolutions in cryo-EM of immature flaviviruses. Finally, we suggest that the immature conformation of the prM-E complex is under strain and 
protonation of His101 of the pr-M linker (SPOV numbering) in the trans-Golgi leads to release of $E$, allowing relaxation into the flat-lying conformation. A topologically feasible, tentative model of the immature-mature reorganization is presented in Supplementary Video 2.

Early work on flavivirus maturation has indicated that furin cleavage of prM does not occur at neutral $\mathrm{pH}^{10}$ (as in the ER or early Golgi), when the virus is in the spiky conformation. This led to the suggestion that the protease recognition site is not exposed. Later modelling based on low resolution data inferred that the furin recognition motif is indeed sterically blocked in the immature conformation ${ }^{30}$. In the current study our map resolution allows us to elucidate the molecular basis of furin site occlusion within the $\mathrm{prM}_{3} \mathrm{E}_{3}$ trimer. However, furin protease is inactivated by binding its prosegment before reaching the low $\mathrm{pH}$ of the TGN, where the inhibitory prosegment is released ${ }^{13}$. If furin is inactive in the ER and early Golgi this begs the question why it is necessary for the virus to obscure the furin site in these early compartments. However, previous studies have shown that furin is occasionally responsible for some proteolytic processing in the ER or early Golgi, for instance if the substrate outcompetes the inhibitory prosegment ${ }^{34,35}$. We suggest that occlusion of the furin site within immature trimers is a critical adaptation for the virus because otherwise high levels of virus expression within an infected cell, combined with high local concentrations of furin recognition motifs on a viral surface could lead to some cleavage events in the ER or early Golgi. As the $\mathrm{pH}$ is neutral in these compartments, the affinity of cleaved pr to $\mathrm{E}$ would be low and some pr could dissociate. In turn this would lead to partially matured virus (which is fusion competent $^{3}$ ) reaching the low $\mathrm{pH}$ TGN, where unproductive fusion would be triggered prematurely.

We have shown that, in addition to Sindbis alphavirus ${ }^{32}$, DENV2, ZIKV, and SPOV all possess a lipid-like density clenched in-between the membrane-associated helices of their glycoproteins. The high resolution map for SPOV allows us to assign the density to a PE type lipid. Previous computational modelling studies, that took lipidomics into account ${ }^{28}$, have estimated that there are around 2400 PE lipids in the dengue virion. Tight binding of $180 \mathrm{PE}$ molecules by all copies of E would constitute the immobilization of $7.5 \%$ of total PE in the virion, a substantial amount. This lipid site may be involved in the stabilization of the mature virus, preventing the space between membrane-associated helices from collapsing and 
ensuring their correct orientations. Given the observation of a structurally equivalent lipid in alphaviruses, it is tempting to speculate that this is a strategy common amongst enveloped viruses. Furthermore, a highly conserved and mutation-sensitive histidine (His447 in SPOV, His437 in DENV2) is located adjacent to the lipid, suggesting a pH-dependent role during the viral lifecycle. Just as small molecules mimicking a lipid pocket-factor in picornaviruses have similarly been successfully employed as viral inhibitors ${ }^{36-38}$, it is apparent that the pocket may be a potential new target for the development of antivirals.

\section{Material and Methods}

\section{Virus sample preparation and inactivation}

SPOV and DENV2 was propagated and prepared as described previously ${ }^{21,39}$. To identify optimal UV exposure conditions for inactivation, virus samples were placed into a UV crosslinker (Uvitec) for different periods of time (from $15 \mathrm{~s}$ to $5 \mathrm{~min}$ ). UV-inactivated virus samples were added to a Vero cell monolayer and incubated for $2 \mathrm{~h}$. Non-UV inactivated virus was used as a control. A plaque assay was performed by topping up the cells with $1.5 \%$ carboxymethyl cellulose and incubation at $37^{\circ} \mathrm{C}$ for 3 days to allow virus infection. Finally, viral foci were visualized via the cross-reactive mouse monoclonal antibody (mAb) 4G2, followed by anti-mouse immunoglobulin conjugated to horse radish peroxidase (HRP) and development by DAB (3,3'Diaminobenzidine) substrate. Although we saw complete inactivation after the minimal exposure of $1 \mathrm{~min}$, we doubled this inactivation time to $2 \mathrm{~min}$ for electron microscopy samples. Following inactivation, a volume of $3.5 \mu \mathrm{l}$ of purified SPOV was pipetted on glow-discharged Quantifoil holey carbon grids ( $1 \mu \mathrm{m}$ spacing, $2 \mu \mathrm{m}$ holes, biocompatible 200 gold mesh) and was blotted for 3.5s before flash-freezing in liquid ethane using a Vitrobot mark IV (FEI). For DENV, Protochips carbon-coated copper C-flat grids (1 $\mu \mathrm{m}$ spacing, $2 \mu \mathrm{m}$ holes) were used. A sample of the quality of UV inactivated virus is shown in Extended Data Fig. 1b.

\section{Cryo-EM data collection and processing}

Cryo-EM movies for SPOV were collected at the Electron Bio-Imaging Centre (eBIC) at Diamond Light Source, UK. A 300 kV Titan Krios instrument (Thermo Fisher Scientific), 
equipped with a K3 (Gatan) direct detector and a GIF Quantum energy filter (Gatan) with 20 eV slit width was utilized. Data were collected automatically using SerialEM 3.7 in superresolution mode (0.4225 ̊̊ per pixel). DENV2 data were collected at the Division of Structural Biology, Oxford, UK, on a 300 kV F30 Polara (Thermo Fisher Scientific) equipped with a K2 Summit (Gatan) direct detector (super resolution mode, $0.44 \AA$ A per pixel) and a GIF Quantum energy filter (Gatan) with $20 \mathrm{eV}$ slit width. Data collection parameters are summarized in Extended Data Table 1.

Motion correction of cryo-EM movies was carried out using MotionCor2-1.1.0 ${ }^{40}$, and 2x binning was applied for super resolution data. Contrast transfer function (CTF) parameters were estimated using Gctf-v.1.06 ${ }^{41}$ (SPOV) and CTFFIND4 ${ }^{42}$ (DENV2). Particles were picked using cryoSPARC v.2.12.043 (SPOV) and Ethan1.2 ${ }^{44}$ (DENV2). Subsequent classification and refinement steps were performed in RELION3.1 ${ }^{45}$. Icosahedral reconstruction (I1 symmetry) of immature SPOV and mature SPOV/DENV2 were carried out using standard methods. Briefly, the initial particle sets were cleaned via 2D/3D classifications runs, followed by masked 3D refinement and post-processing. CTF refinement and Bayesian polishing in RELION3.1 were used to further improve the density and resolution of the reconstructions. The numbers of initial and final particles are summarized for all samples in Extended Data Table 1.

To acquire high resolution maps of immature spikes we used Localized Reconstruction ${ }^{22}$ within Scipion v.2.0 $0^{46,47}$ to obtain coordinates, CTF parameters, and orientations of individual spike sub-particles and carried out processing of sub-particles in RELION. An overview of the workflow is shown in Extended Data Figure 2. Briefly, we extracted sub-particles of immature trimeric spikes from 42,880 viruses. The resulting 2,572,800 sub-particles were then subjected to 3D classification without alignment. The 3D classes revealed a substantial amount of heterogeneity in the spikes (see Extended Data Figure 2). This underscores why icosahedral reconstructions of immature flaviviruses would be limited in resolution, as heterogeneous spikes would be averaged when applying symmetry. In addition, virus preparations typically contain partially immature particles ${ }^{6}$, and mature patches on such hybrid particles may also contribute to heterogeneity. We selected two classes with a total of 371,915 sub-particles for further processing. A second round of classification, followed by 
masked refinement and post-processing yielded a $4.2 \AA$ resolution map of the $\mathrm{prM}_{3} \mathrm{E}_{3}$ trimeric spike reconstructed from 305,017 sub-particles. Although the quality of the density had dramatically improved by localized reconstruction, we attempted to improve the resolution further to aid in model building and refinement. We performed focused classification and refinement on $\mathrm{prM}_{1} \mathrm{E}_{1}$ monomers and finally obtained a map at $3.8 \AA$ resolution, reconstructed from 281,619 sub-particles. This map served as the basis for initial building of an atomic model, while the $4.2 \AA$ resolution map of $\operatorname{prM}_{3} \mathrm{E}_{3}$ was used to refine an atomic model of the full trimer. Local resolution values of the immature localized reconstructions and map vs model FSC plots are shown in Extended Data Figure 3.

All atomic structures in this study were refined through alternating cycles of real space refinement in PHENIX v.1.17.1 ${ }^{48}$ and manual building in Coot v.0.8.9.2 $2^{49}$. Model geometry was validated using MolProbity ${ }^{50}$. Geometry statistics, model B factors, and map vs model crosscorrelation values are shown in Extended Data Table 1 for all refined models.

\section{Construction of mutant viruses}

To introduce amino acid exchanges at the lipid pocket, site-directed mutagenesis of prM/E in a pHLsec vector ${ }^{51}$ was performed using Pfx DNA polymerase (Invitrogen). The pHLsec-prM/E wild-type and point mutants were then further amplified via polymerase chain reaction (PCR). For mutant virus construction, we employed the Gibson assembly technique as described previously ${ }^{33,52}$. Twenty microliters of the Gibson assembly reactions were diluted in OptiMinimal Essential Media I (Thermo Fisher Scientific), mixed with Lipofectamin 2000 (Invitrogen), before transfecting human embryonic kidney 293T cells (HEK-293T) for $4 \mathrm{~h}$ at $37^{\circ} \mathrm{C}$. The medium was then exchanged to Dulbecco's Modified Eagle Medium (DMEM, Thermo Fisher Scientific), supplemented with $10 \%$ heat-inactivated fetal calf serum (FCS). After overnight incubation, the medium was removed and replaced by Ultradoma ProteinFree (LONZA). The cultured medium was harvested and replenished on the second, third and fourth days after transfection. Cell-free supernatants were collected and stored at $-80{ }^{\circ} \mathrm{C}$. Wild-type and mutant viruses from transfected HEK-293T cells were further propagated in C6/36 cells. Medium was changed on the fourth day and then every 3 days. Viral production and titres were determined by enzyme-linked immunosorbent assay (ELISA) and focusforming assay, as described previously ${ }^{53}$. Briefly, to determine DENV production, virus 
supernatants were captured onto plates coated with antibody 4G2 and then incubated with antibody 749B12 (human anti-fusion loop epitope), followed by alkaline phosphotaseconjugated anti-human IgG (A9544; Sigma). Reactions were developed by addition of paranitrophenylphosphate substrate and were stopped by addition of $\mathrm{NaOH}$. The absorbance was measured at $405 \mathrm{~nm}$.

\section{Data availability}

All data are available from the corresponding authors and/or are included in the manuscript. Cryo-EM density maps and atomic coordinates of models have been deposited in the Electron Microscopy Data Bank and the Protein Data Bank, respectively. Atomic coordinates are deposited under the PDB accession codes XXXX (mature DENV2, icosahedral reconstruction), XXXX (mature SPOV, icosahedral reconstruction), XXXX (immature SPOV trimeric spike, localized reconstruction), $X X X X$ (immature $\operatorname{prM}_{1} \mathrm{E}_{1}$ monomer, localized reconstruction), and XXXX (immature SPOV, icosahedral reconstruction). Cryo-EM maps are deposited under the EMD accession codes EMD-XXXX (mature DENV2, icosahedral reconstruction), EMD-XXXX (mature SPOV, icosahedral reconstruction), EMD-XXXX (immature SPOV trimeric spike, localized reconstruction), EMD-XXXX (immature $\operatorname{prM}_{1} \mathrm{E}_{1}$ heterodimer, localized reconstruction), and EMD-XXXX (immature SPOV, icosahedral reconstruction).

\section{Acknowledgements}

This work was supported by the Wellcome Trust, UK. Microscopy was partly conducted at the OPIC electron microscopy facility, which was funded by a Wellcome JIF award (060208/Z/00/Z) and is supported by a Wellcome equipment grant (093305/Z/10/Z). The Wellcome Trust is also acknowledged for providing administrative support (Grant $075491 / Z / 04)$. GRS is a Wellcome Trust senior investigator. MR is supported by a Wellcome Trust fellowship (204703/Z/16/Z). JMG is supported by a Wellcome Investigator Award (200835/Z/16/Z). ISM was supported by an MRC studentship (1374922). We thank B. Qureshi for support with electron microscopy, the staff of the Electron Bio-Imaging Centre (eBIC), especially D. Clare, for assistance with data collection and advice on data processing. We also thank L. Mendonça, T. Frosio, and members of the P. Zhang group for scientific discussions. Computation used the Oxford Biomedical Research Computing (BMRC) facility, a joint 
development between the Wellcome Centre for Human Genetics and the Big Data Institute, supported by Health Data Research UK and the NIHR Oxford Biomedical Research Centre. Financial support was provided by a Wellcome Trust Core Award (203141/Z/16/Z). The views expressed are those of the author(s) and not necessarily those of the NHS, the NIHR or the Department of Health.

\section{Author Contributions}

M.R., W.D., J.M., G.R.S., and J.M.G. conceived and designed the study. W.D. and J.M. prepared and purified virus samples and performed Gibson assembly. M.R., L.C., and I.S.M., prepared vitrified cryogenic electron microscopy grids. M.R., L.C., D.K., and J.K., screened grids. M.R., L.C., D.K., S.F.H., and A.K. collected cryo-EM data. M.R. carried out cryo-EM data processing and model building/refinement with assistance from L.C., I.S.M., and S.L.I. M.R. wrote the manuscript, with input from all the authors.

\section{Competing Interests}

The authors declare no competing interests.

\section{References}

1. Bhatt, S. et al. The global distribution and burden of dengue. Nature 496, 504-507 (2013).

2. Zhang, X. et al. Cryo-EM structure of the mature dengue virus at 3.5-Å resolution. Nat. Struct. Mol. Biol. 20, 105-110 (2013).

3. Hasan, S. S., Sevvana, M., Kuhn, R. J. \& Rossmann, M. G. Structural biology of Zika virus and other flaviviruses. Nature Structural and Molecular Biology 25, 13-20 (2018).

4. Sevvana, M. et al. Refinement and Analysis of the Mature Zika Virus Cryo-EM Structure at 3.1 Å Resolution. Structure 26, 1169-1177.e3 (2018).

5. Lok, S. M. The Interplay of Dengue Virus Morphological Diversity and Human Antibodies. Trends in Microbiology 24, 284-293 (2016).

6. Slon Campos, J. L., Mongkolsapaya, J. \& Screaton, G. R. The immune response against flaviviruses. Nature Immunology 19, 1189-1198 (2018). 
7. Stiasny, K. \& Heinz, F. X. Flavivirus membrane fusion. Journal of General Virology 87, 2755-2766 (2006).

8. Kostyuchenko, V. A., Zhang, Q., Tan, J. L., Ng, T.-S. \& Lok, S.-M. Immature and Mature Dengue Serotype 1 Virus Structures Provide Insight into the Maturation Process. J. Virol. 87, 7700-7707 (2013).

9. Prasad, V. M. et al. Structure of the immature Zika virus at 9 A resolution. Nat. Struct. Mol. Biol. 24, 184-186 (2017).

10. Stadler, K., Allison, S. L., Schalich, J. \& Heinz, F. X. Proteolytic activation of tick-borne encephalitis virus by furin. J. Virol. 71, 8475-8481 (1997).

11. Yu, I.-M. et al. Association of the pr Peptides with Dengue Virus at Acidic pH Blocks Membrane Fusion. J. Virol. 83, 12101-12107 (2009).

12. Yu, I. M. et al. Structure of the immature dengue virus at low $\mathrm{pH}$ primes proteolytic maturation. Science (80-. ). 319, 1834-1837 (2008).

13. Seidah, N. G. et al. The activation and physiological functions of the proprotein convertases. International Journal of Biochemistry and Cell Biology 40, 1111-1125 (2008).

14. Zhang, Y. et al. Structures of immature flavivirus particles. EMBO J. 22, 2604-2613 (2003).

15. Tan, T. Y. et al. Capsid protein structure in Zika virus reveals the flavivirus assembly process. Nat. Commun. 11, (2020).

16. Wolfe, M. S., Calisher, C. H. \& Mcguire, K. Spondweni Virus Infection in a Foreign Resident of Upper Volta. Lancet 320, 1306-1308 (1982).

17. Haddow, A. D. \& Woodall, J. P. Distinguishing between Zika and Spondweni viruses. Bulletin of the World Health Organization 94, 711-711A (2016).

18. MacNamara, F. N. Zika virus: A report on three cases of human infection during an epidemic of jaundice in Nigeria. Trans. R. Soc. Trop. Med. Hyg. 48, 139-145 (1954).

19. White, S. K., Lednicky, J. A., Okech, B. A., Morris, J. G. \& Dunford, J. C. Spondweni virus in field-caught culex quinquefasciatus mosquitoes, Haiti, 2016. Emerging Infectious Diseases 24, 1765-1767 (2018).

20. Pierson, T. C. \& Diamond, M. S. The continued threat of emerging flaviviruses. Nat. Microbiol. 5, (2020).

21. Salazar, V. et al. Dengue and Zika Virus Cross-Reactive Human Monoclonal Antibodies 
Protect against Spondweni Virus Infection and Pathogenesis in Mice. Cell Rep. 26, 1585-1597.e4 (2019).

22. Ilca, S. L. et al. Localized reconstruction of subunits from electron cryomicroscopy images of macromolecular complexes. Nat. Commun. 6, 8843 (2015).

23. Lin, Y.-J. \& Wu, S.-C. Histidine at Residue 99 and the Transmembrane Region of the Precursor Membrane prM Protein Are Important for the prM-E Heterodimeric Complex Formation of Japanese Encephalitis Virus. J. Virol. 79, 8535-8544 (2005).

24. Zheng, A., Yuan, F., Kleinfelter, L. M. \& Kielian, M. A toggle switch controls the low $\mathrm{pH}$-triggered rearrangement and maturation of the dengue virus envelope proteins. Nat. Commun. 5, 3877 (2014).

25. Dubayle, J. et al. Site-specific characterization of envelope protein N-glycosylation on Sanofi Pasteur's tetravalent CYD dengue vaccine. Vaccine 33, 1360-1368 (2015).

26. Carbaugh, D. L., Baric, R. S. \& Lazear, H. M. Envelope Protein Glycosylation Mediates Zika Virus Pathogenesis. J. Virol. 93, (2019).

27. Fontes-Garfias, C. R. et al. Functional Analysis of Glycosylation of Zika Virus Envelope Protein. Cell Rep. 21, 1180-1190 (2017).

28. Reddy, T. \& Sansom, M. S. P. The Role of the Membrane in the Structure and Biophysical Robustness of the Dengue Virion Envelope. Structure 24, 375-382 (2016).

29. Zhang, Y. et al. Conformational changes of the flavivirus E glycoprotein. Structure 12, 1607-1618 (2004).

30. Li, L. et al. The flavivirus precursor membrane-envelope protein complex: Structure and maturation. Science (80-. ). 319, 1830-1834 (2008).

31. Jenkin, H. M., McMeans, E., Anderson, L. E. \& Yang, T. K. Comparison of phospholipid composition of Aedes aegypti and Aedes albopictus cells obtained from logarithmic and stationary phases of growth. Lipids 10, 686-694 (1975).

32. Chen, L. et al. Implication for alphavirus host-cell entry and assembly indicated by a 3.5Å resolution cryo-EM structure. Nat. Commun. 9, (2018).

33. Gibson, D. G. et al. Enzymatic assembly of DNA molecules up to several hundred kilobases. Nat. Methods 6, 343-345 (2009).

34. Salvas, A., Benjannet, S., Reudelhuber, T. L., Chrétien, M. \& Seidah, N. G. Evidence for proprotein convertase activity in the endoplasmic reticulum/early Golgi. FEBS Lett. 579, 5621-5625 (2005). 
35. Bass, J., Turck, C., Rouard, M. \& Steiner, D. F. Furin-mediated processing in the early secretory pathway: Sequential cleavage and degradation of misfolded insulin receptors. Proc. Natl. Acad. Sci. U. S. A. 97, 11905-11909 (2000).

36. Plevka, P. et al. Structure of human enterovirus 71 in complex with a capsid-binding inhibitor. Proc. Natl. Acad. Sci. U. S. A. 110, 5463-5467 (2013).

37. De Colibus, L. et al. More-powerful virus inhibitors from structure-based analysis of HEV71 capsid-binding molecules. Nat. Struct. Mol. Biol. 21, 282-288 (2014).

38. Grant, R. A. et al. Structures of poliovirus complexes with anti-viral drugs: implications for viral stability and drug design. Curr. Biol. 4, 784-797 (1994).

39. Renner, M. et al. Characterization of a potent and highly unusual minimally enhancing antibody directed against dengue virus. Nat. Immunol. 1 (2018). doi:10.1038/s41590018-0227-7

40. Zheng, S. Q. et al. MotionCor2: Anisotropic correction of beam-induced motion for improved cryo-electron microscopy. Nature Methods 14, 331-332 (2017).

41. Zhang, K. Gctf: Real-time CTF determination and correction. J. Struct. Biol. 193, 1-12 (2016).

42. Rohou, A. \& Grigorieff, N. CTFFIND4: Fast and accurate defocus estimation from electron micrographs. J. Struct. Biol. 192, 216-221 (2015).

43. Punjani, A., Rubinstein, J. L., Fleet, D. J. \& Brubaker, M. A. CryoSPARC: Algorithms for rapid unsupervised cryo-EM structure determination. Nat. Methods 14, 290-296 (2017).

44. Kivioja, T., Ravantti, J., Verkhovsky, A., Ukkonen, E. \& Bamford, D. Local average intensity-based method for identifying spherical particles in electron micrographs. J. Struct. Biol. 131, 126-134 (2000).

45. Zivanov, J. et al. New tools for automated high-resolution cryo-EM structure determination in RELION-3. Elife 7, (2018).

46. de la Rosa-Trevín, J. M. et al. Scipion: A software framework toward integration, reproducibility and validation in 3D electron microscopy. J. Struct. Biol. 195, 93-99 (2016).

47. Abrishami, V. et al. Localized reconstruction in scipion expedites the analysis of symmetry mismatches in Cryo-EM data. Prog. Biophys. Mol. Biol. (2020). doi:10.1016/j.pbiomolbio.2020.05.004 
48. Afonine, P. V. et al. New tools for the analysis and validation of cryo-EM maps and atomic models. Acta Crystallogr. Sect. D Struct. Biol. 74, 814-840 (2018).

49. Emsley, P. \& Cowtan, K. Coot : model-building tools for molecular graphics. Acta Crystallogr. Sect. D Biol. Crystallogr. 60, 2126-2132 (2004).

50. Chen, V. B. et al. MolProbity : all-atom structure validation for macromolecular crystallography. Acta Crystallogr. Sect. D Biol. Crystallogr. 66, 12-21 (2010).

51. Aricescu, A. R., Lu, W. \& Jones, E. Y. A time- and cost-efficient system for high-level protein production in mammalian cells. Acta Crystallogr. Sect. D Biol. Crystallogr. 62, 1243-1250 (2006).

52. Siridechadilok, B. et al. A Simplified Positive-Sense-RNA Virus Construction Approach That Enhances Analysis Throughput. J. Virol. 87, 12667-12674 (2013).

53. Dejnirattisai, W. et al. A new class of highly potent, broadly neutralizing antibodies isolated from viremic patients infected with dengue virus. Nat. Immunol. 16, 170-177 (2015). 


\section{Figures}
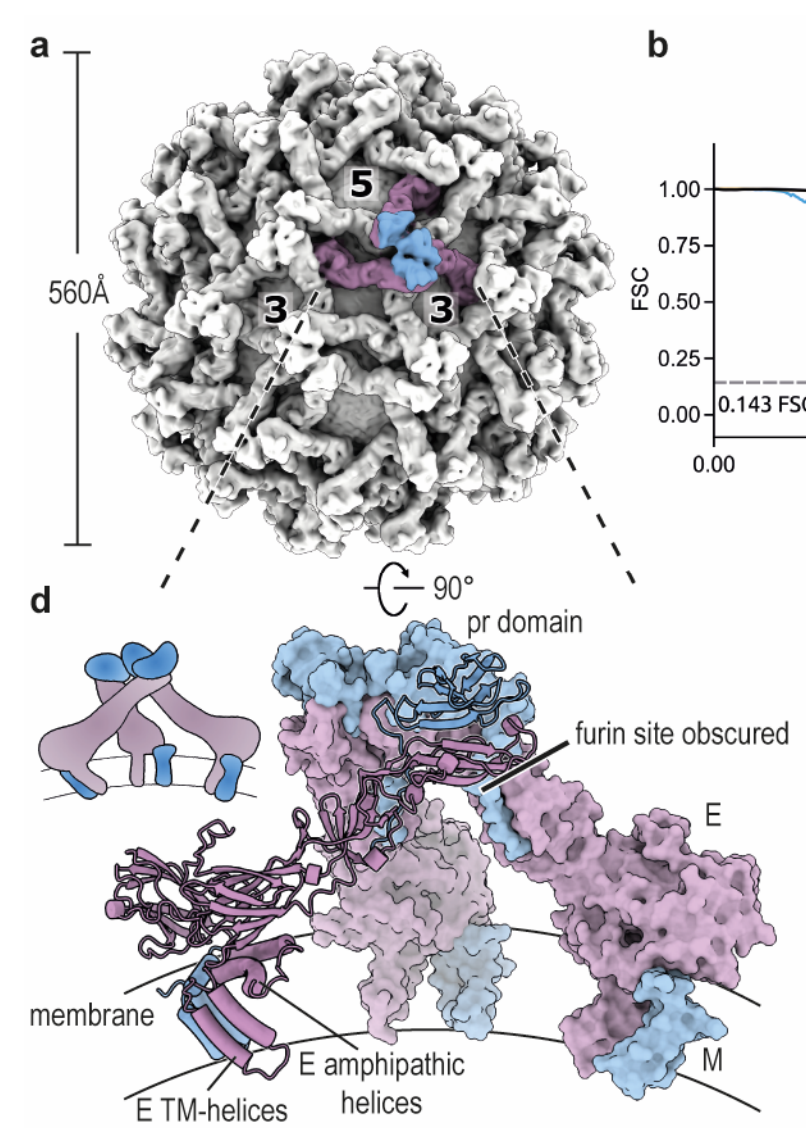
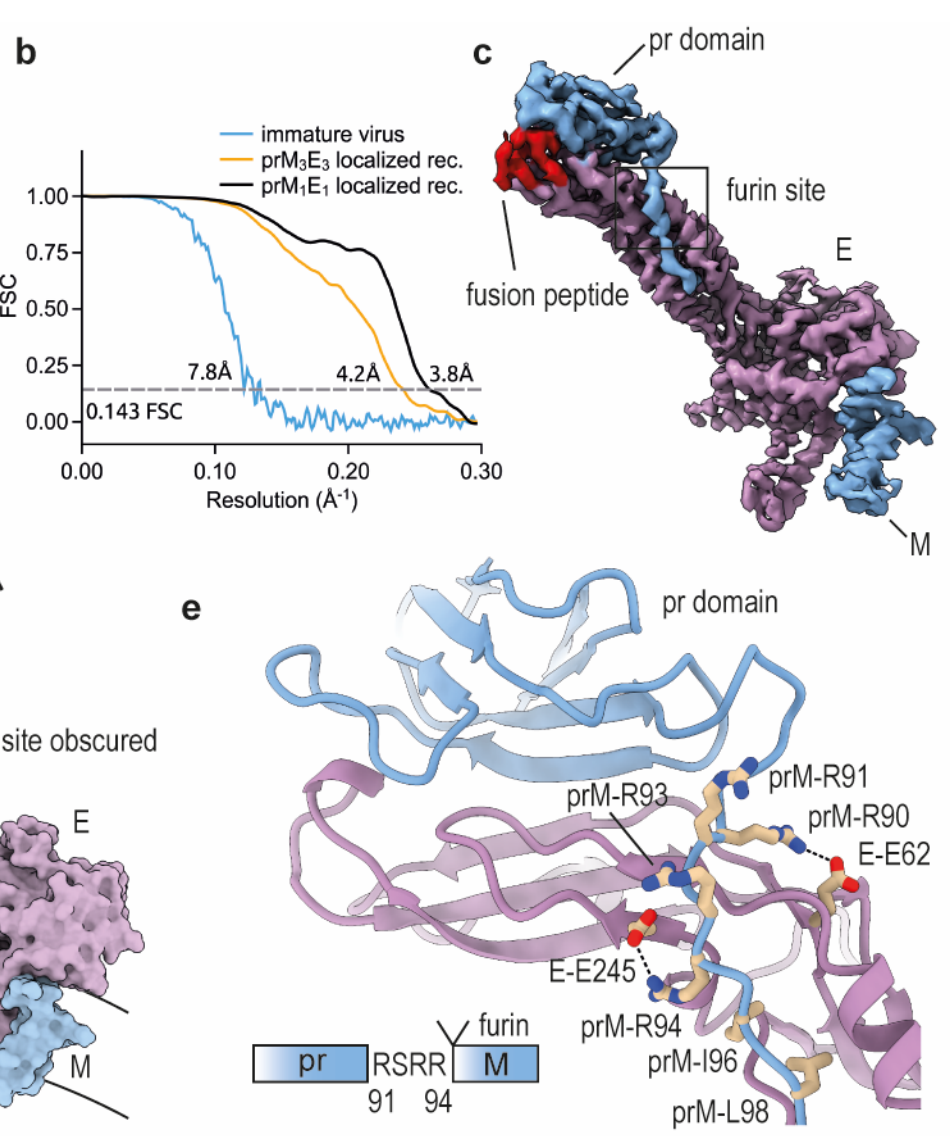

Fig. 1 | Cryo-EM structures of immature SPOV. a, Cryo-EM density map of immature SPOV (icosahedral symmetry applied). Bold numbers indicate three-fold and five-fold vertices of the virion. The $\mathrm{prM}_{3} \mathrm{E}_{3}$ trimer of one asymmetric unit is coloured (prM in blue, E in purple). Approximate dimensions of the virion are indicated by the accompanying scale bar. $\mathbf{b}$, Fourier shell correlation (FSC) plots of reconstructions using gold-standard refinement in RELION. Approximate map resolutions according to the $0.143 \mathrm{FSC}$ cutoff are indicated for all reconstructions. Curves are shown for masked maps. c, Cryo-EM density map of the $\operatorname{prM}_{1} \mathrm{E}_{1}$ complex at 3.8 Å resolution, obtained via localized reconstruction and focused refinement. The map served as basis for building of an initial atomic model. $E$ is coloured in purple, prM in blue. Locations of the furin protease recognition motif and fusion peptide are indicated. $\mathbf{d}$, Atomic model of the $\mathrm{prM}_{3} \mathrm{E}_{3}$ trimeric spike, refined against the $4.2 \AA$ resolution map (orientation rotated by $90^{\circ}$ relative to panel a). One copy of prM1E1 is shown in ribbon representation, and the two others as surfaces. The viral membrane is shown schematically. A cartoon depicting the organization of the trimer is shown for clarity. e, Close-up of the area surrounding the furin recognition motif as indicated in panel C. E and prM residues involved in stabilizing the site are labelled. A schematic is included at the bottom of the panel showing the sequence after which furin cleaves pr and $\mathrm{M}$. 
a

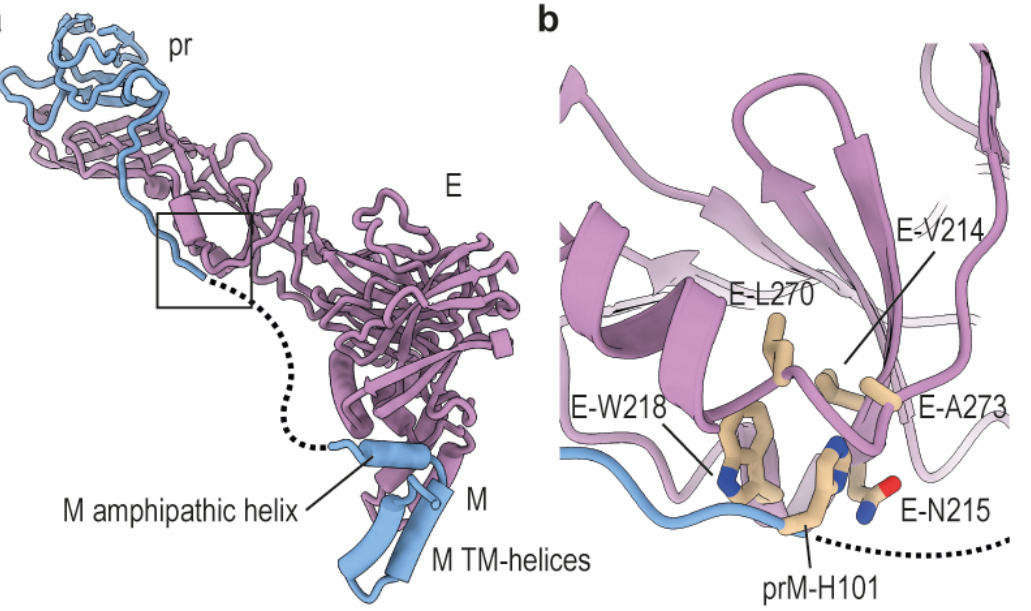

C

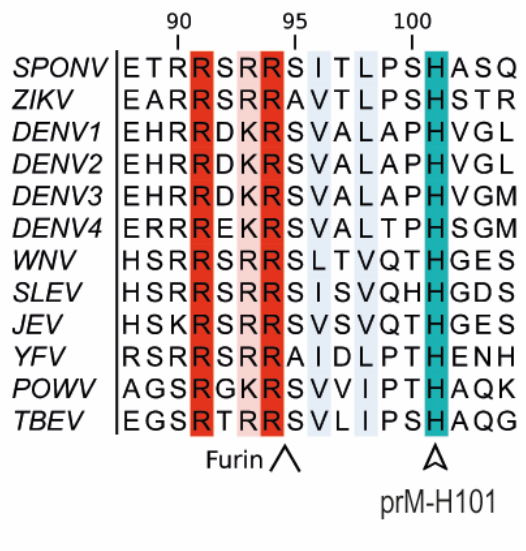

Fig. 2 Anchoring of the pr-M linker to E. a, Zoomed out view of $\operatorname{prM}_{1} \mathrm{E}_{1}$ depicting the disordered linker (covering $\sim 55 \AA$ ) connecting pr and $\mathrm{M}$ as a dotted line. $\mathbf{b}$, Zoomed-in view of the region indicated in panel a. A hydrophobic pocket on the surface of $\mathrm{E}$ is shown, into which prM-H101 is inserted. Involved E and prM residues are labelled. c, Multiple sequence alignment (MSA) of flaviviral prM sequences. The positions of the conserved prM-H101 (SPOV numbering) is indicated, as well as the upstream furin site. Abbreviations: SPONV: Spondweni virus, ZIKV: Zika virus, DENV: Dengue virus, WNV: West Nile virus, SLEV: Saint Louis encephalitis virus, JEV: Japanese encephalitis virus, YFV: Yellow Fever virus, POWV: Powassan virus, TBEV: Tick-borne encephalitis virus. 

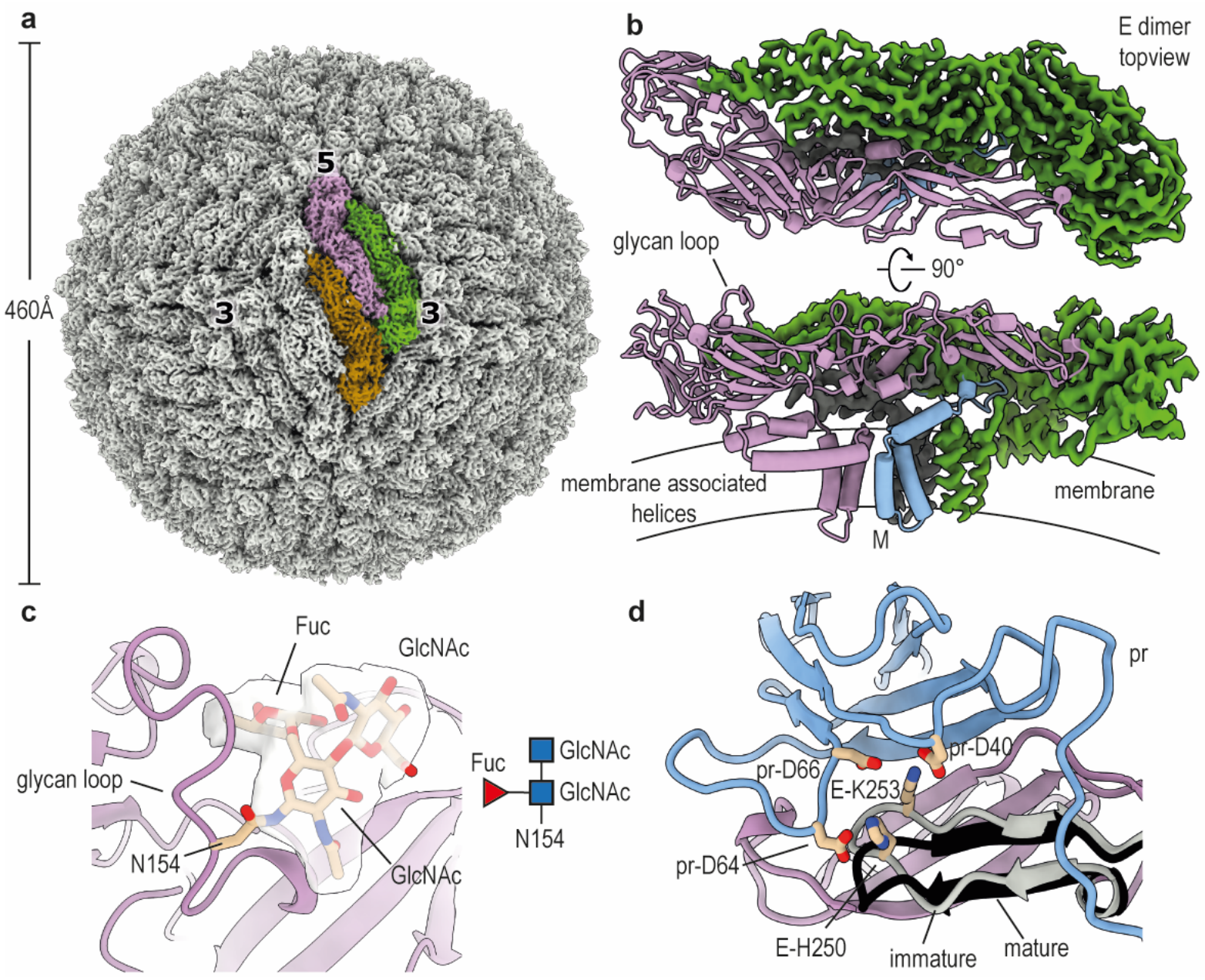

Fig. 3 | 2.6 Å resolution cryo-EM structure of mature SPOV. a, Cryo-EM density map of mature SPOV. Bold numbers indicate three-fold and five-fold vertices of the virion. Each icosahedral asymmetric unit (ASU) contains three copies of $E$ (coloured brown, purple, and green for one ASU) and three copies of $M$, concealed below the E proteins. Approximate dimensions of the virion are indicated by the accompanying scale bar. $\mathbf{b}$, Top-view and side-view of an antiparallel dimer of $E$, which compose the surface of the mature virus. One copy is depicted in ribbon representation (purple), while for the other copy the cryo-EM map is shown (green). The M protein is indicated in the side-view, as well as a schematic of the viral membrane. A surface exposed loop containing the glycan site is labelled. c, Close up view showing the density map of the glycan linked to N154 of E. There was clear density for the two first N-acetylglucosamines (GlcNac) and core fucosylation (Fuc). d, Superposition of the pr-binding interface of $E$ in mature and immature states. Comparison shows that a hairpin close to the pr-binding site of $E$ shifts its position to better engage $\mathrm{pr}$ (immature hairpin in grey, mature in black). Residues on the hairpin involved in binding pr are shown as sticks and labelled. 


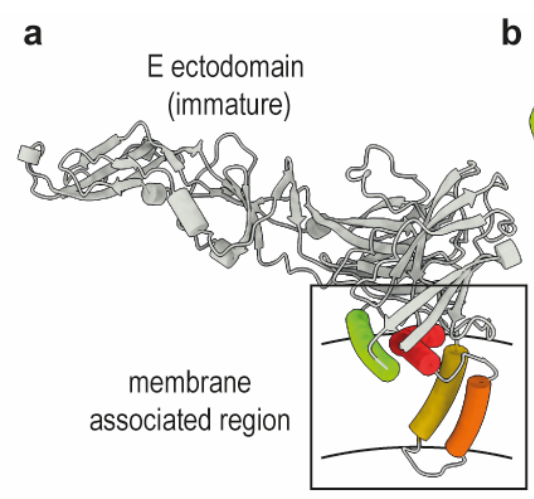

b

immature SPOV

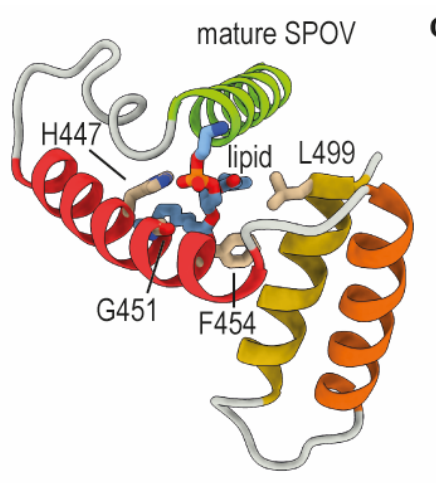

C

\begin{tabular}{|c|c|}
\hline & 450 \\
\hline PONV & $\mathrm{FVHQVFGSA}$ \\
\hline ZIKV & $G \perp H Q \mid F G A A$ \\
\hline DENV1 & LIHQIFGTA \\
\hline DENV2 & A L HQVFGA I \\
\hline DENV3 & $M V H Q I F G S A$ \\
\hline DENV4 & $A \vee H Q \vee F G S V$ \\
\hline$W N V$ & $A \vee H Q \vee F G G A$ \\
\hline SLEV & $A \vee H Q \vee F G G A$ \\
\hline JEV & $A \vee H Q \vee F G G A$ \\
\hline YFV & GIHTVFGSA \\
\hline POWV & A I H T V LGGA \\
\hline TBEV & $A \vee H T V L G G A$ \\
\hline
\end{tabular}

e
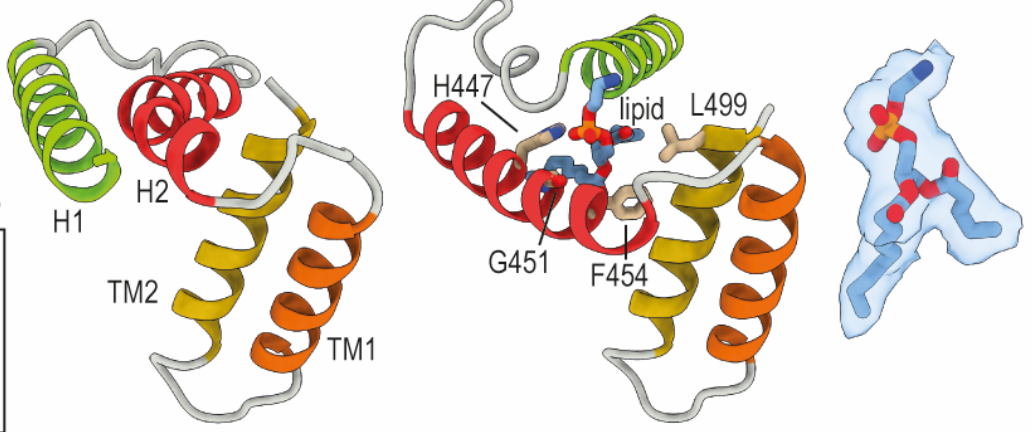

mature ZIKV

f mature DENV2

g

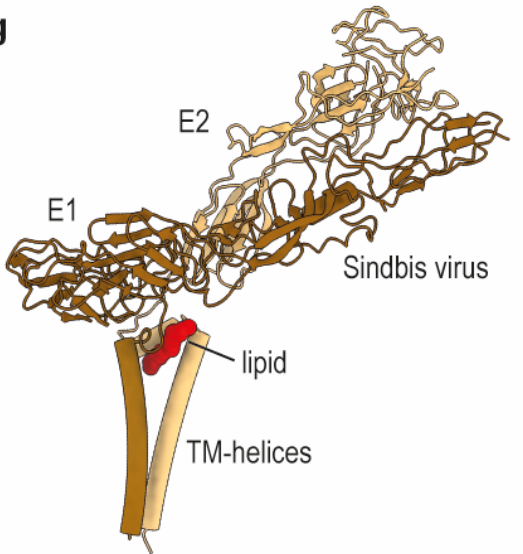

h

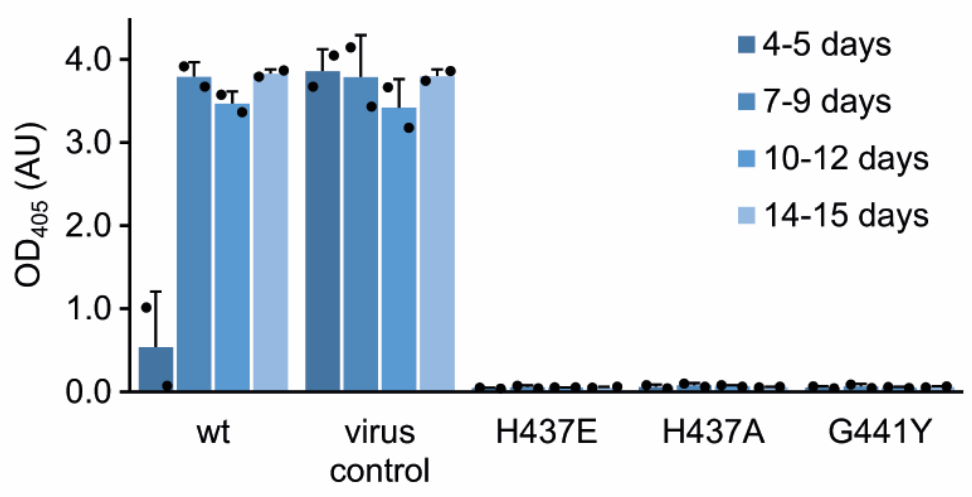

Fig. 4 | Formation of a lipid pocket by rearrangement of membrane-associated helices. a, Position and organization of membrane associated helices in immature E. Two amphipathic helices lie flat on the membrane (coloured green and red), while two transmembrane (TM) helices span it (coloured yellow and orange). $\mathbf{b}$, Close up view of the membrane-associated helices of immature $E$ and mature $E$ of SPOV. Amphipathic helices are numbered $\mathrm{H} 1$ and $\mathrm{H} 2$, TM helices TM1 and TM2. In mature $\mathrm{E}$ (on the right) the amphipathic helices have reorganized, opening up a pocket that is filled with density resembling a phosphatidylethanolamine (PE) lipid. The lipid is shown in stick representation. The density fit is shown separately in panel c for clarity. Residues in close vicinity are shown as sticks and labelled appropriately. c, Lipid fitted into the cryo-EM map at the binding pocket. d, MSA of E sequences located next to the lipid, highlighting the conservation of H447 and G451 (SPOV numbering). Virus abbreviations as in Fig. 2. e, Density present in the pocket of mature ZIKV (accession code: EMDB-7543). f, Density present in the pocket 
of mature DENV2 (this study). g, Structure of Sindbis virus E1 and E2 (pdb: 6IMM) illustrating the similarity of the position of a glycoprotein associated lipid (coloured in red). $\mathbf{h}$, Virus recovery after Gibson assembly of mutant viruses. Wild-type and mutants of DENV2/16681 were constructed via Gibson assembly and propagated in C6/36 cells. Production of virus was assessed after given intervals by ELISA. Cells infected with virus stock served as positive control.

\section{Supplementary Information}

Video 1 | Cryo-EM map of prM $\mathrm{B}_{1}$. This video shows an overview of the quality of the $\operatorname{prM}_{1} \mathrm{E}_{1}$ cryo-EM map, obtained by localized reconstruction and focused refinement.

\section{Video 2 | Hypothetical model of the structural transition from immature spiky to smooth} virion morphologies. This video shows a hypothetical model of how the virus with immature trimeric $\mathrm{prM}_{3} \mathrm{E}_{3}$ surface spikes changes its conformation to the smooth state. These changes represent the $\mathrm{pH}$ transition along the secretory pathway, going from the $\mathrm{ER}$ (neutral $\mathrm{pH}$ ) to the late Golgi (acidic pH). The video highlights how the furin recognition motif is concealed in the spiky virus, and then becomes exposed at the surface in our model of the smooth, prbound virus. 
bioRxiv preprint doi: https://doi org/10.1101/2020.06.07.138669. this version posted June 7, 2020. The copyright holder for this preprint (which was not certified by peer review) is the author/funder, who has granted bioRxiv a license to display the preprint in perpetuity. It is made available under aCC-BY-NC-ND 4.0 International license.

\section{Extended Data}

a

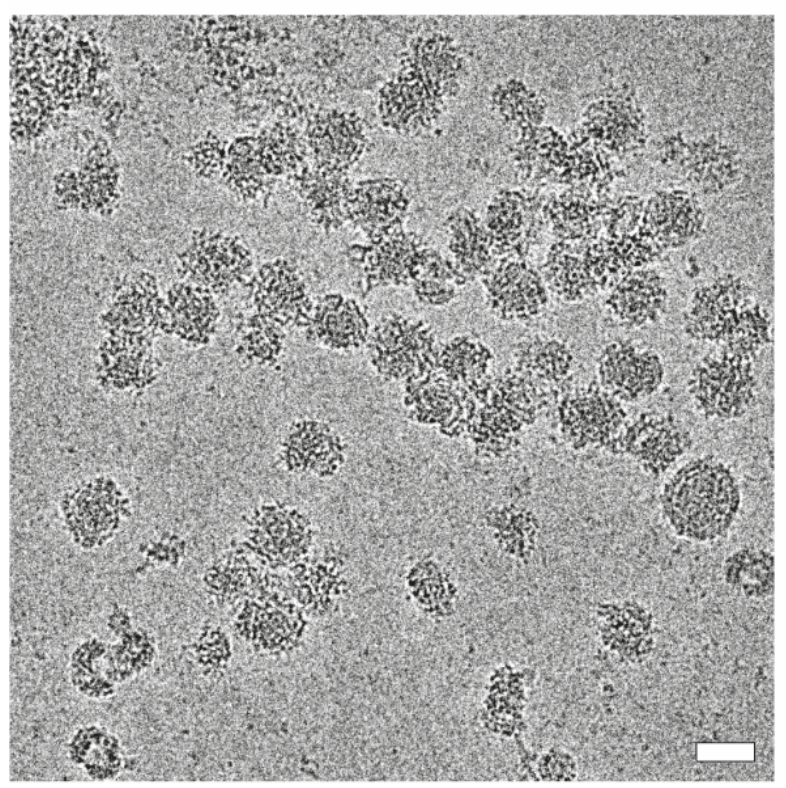

b

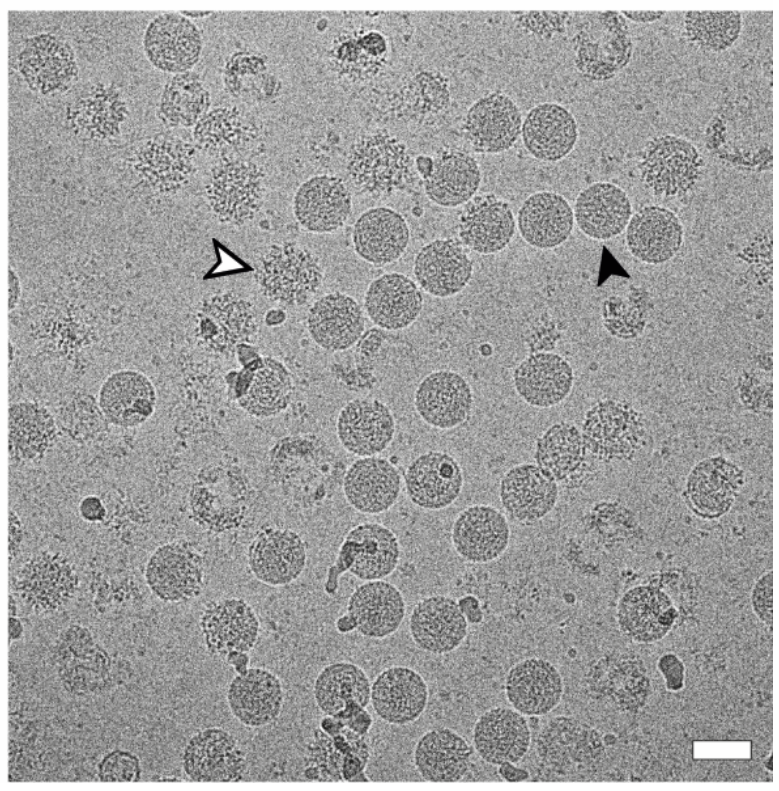

Extended Data Fig. 1 | UV inactivation procedure. a, Representative micrograph of inactivated SPOV particles after 5 minutes of UV exposure. The particles are heavily distorted and aggregated. White bar 50nm. b, Representative micrograph after optimized UV inactivation. Virus was exposed to UV light for varying periods of time (see Methods), followed by plaque assay to assess viricidal effect. The minimum exposure time of $1 \mathrm{~min}$ was identified, after which no plaques could be detected. For cryo-EM samples, we used an exposure time of 2 mins. The particles are of high quality and well-separated. Both mature particles (black arrow) as well as immature particles (white arrow) are present in the sample. White bar $\sim 50 \mathrm{~nm}$. 
bioRxiv preprint doi: https//doi org/10.1101/2020 06.07.138669; this version posted June 7, 2020. The copyright holder for this preprin (which was not certified by peer review) is the author/funder, who has granted bioRxiv a license to display the preprint in perpetuity. It is made available under aCC-BY-NC-ND 4.0 International license.

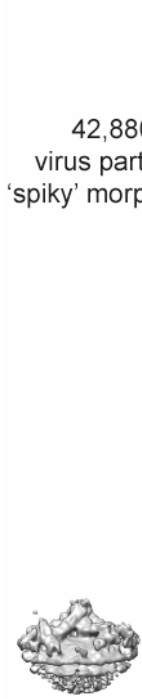

$20.6 \%$

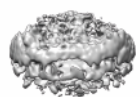

$10.0 \%$

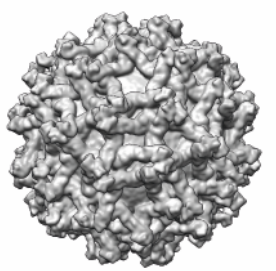

8.6 A Resolution

Localized extraction (x60 particles)

\section{2,572,800 subparticles}

3D class.

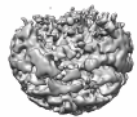

$0.6 \%$

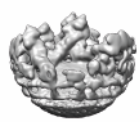

$8.3 \%$
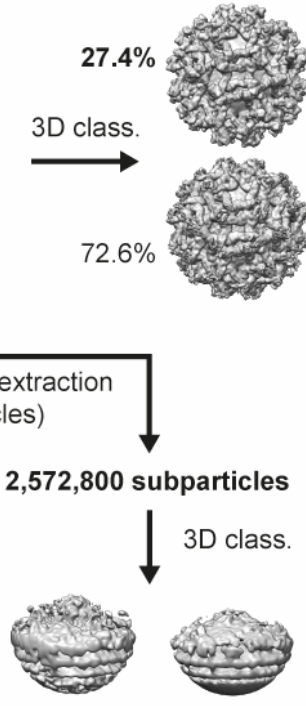
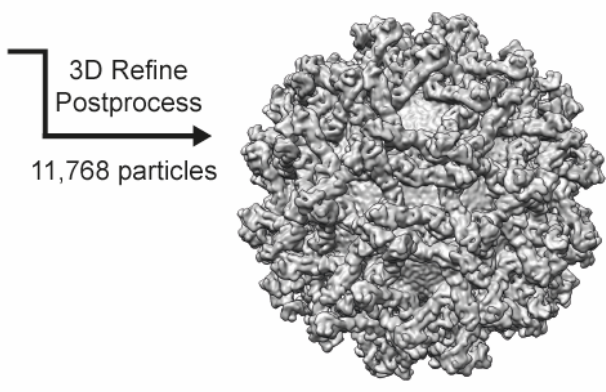

Immature virus 7.8 A Resolution
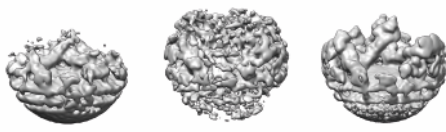

$0.7 \%$

$6.4 \%$

$31.6 \%$

371,915 subparticles

3D Refine

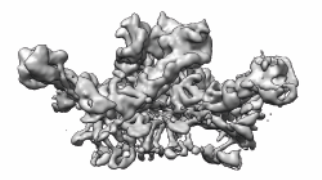

$4.4 \AA$ Resolution
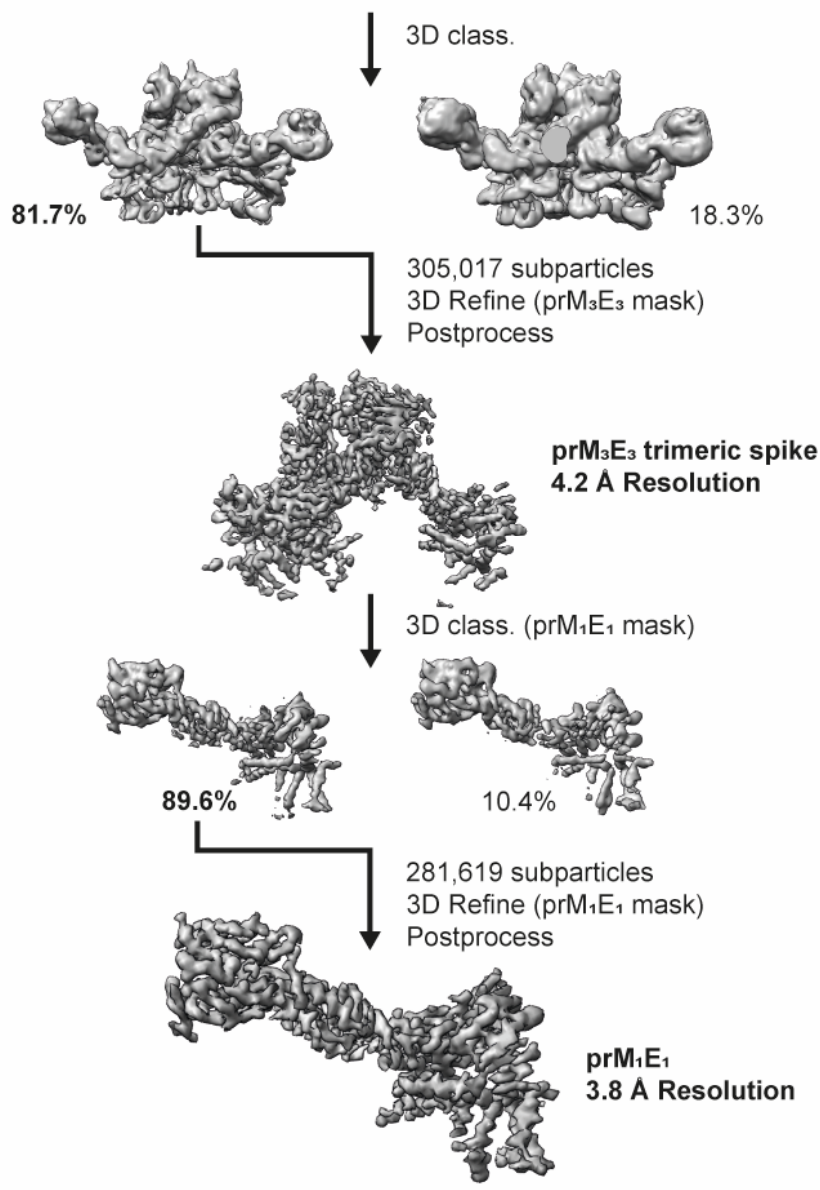
bioRxiv preprint doi: https://doi.org/10.1101/2020.06.07.138669; this version posted June 7, 2020. The copyright holder for this preprint (which was not certified by peer review) is the author/funder, who has granted bioRxiv a license to display the preprint in perpetuity. It is made available under aCC-BY-NC-ND 4.0 International license.

Extended Data Fig. 2 | Cryo-EM processing flowchart of immature SPOV. Flowchart of processing steps of immature SPOV, going from immature virions, to localized reconstruction of trimeric spikes, to focussed refinement of $\operatorname{prM}_{1} \mathrm{E}_{1}$ monomers. 
bioRxiv preprint doi: https://doi org/10.1101/2020.06.07.138669; this version posted June 7,2020 . The copyright holder for this preprint (which was not certified by peer review) is the author/funder, who has granted bioRxiv a license to display the preprint in perpetuity. It is made available under aCC-BY-NC-ND 4.0 International license.

a

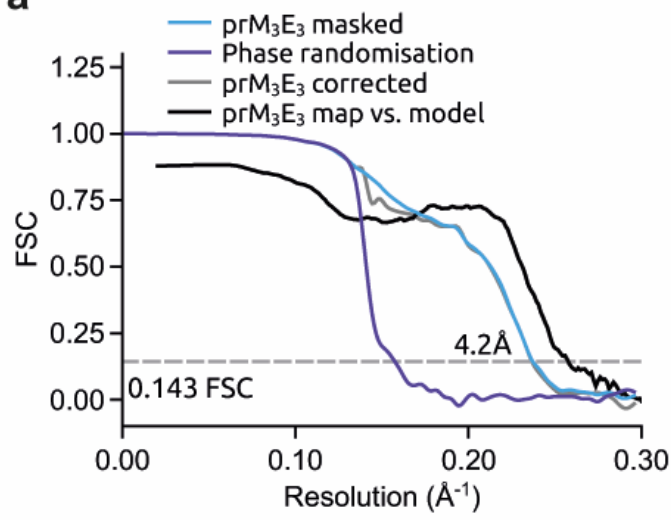

C

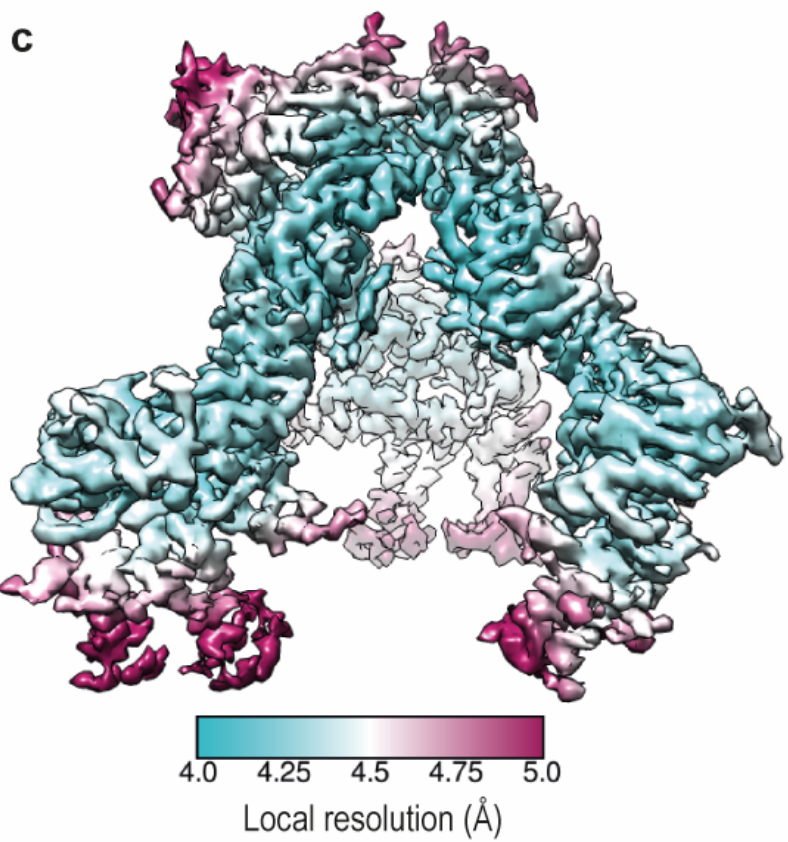

e

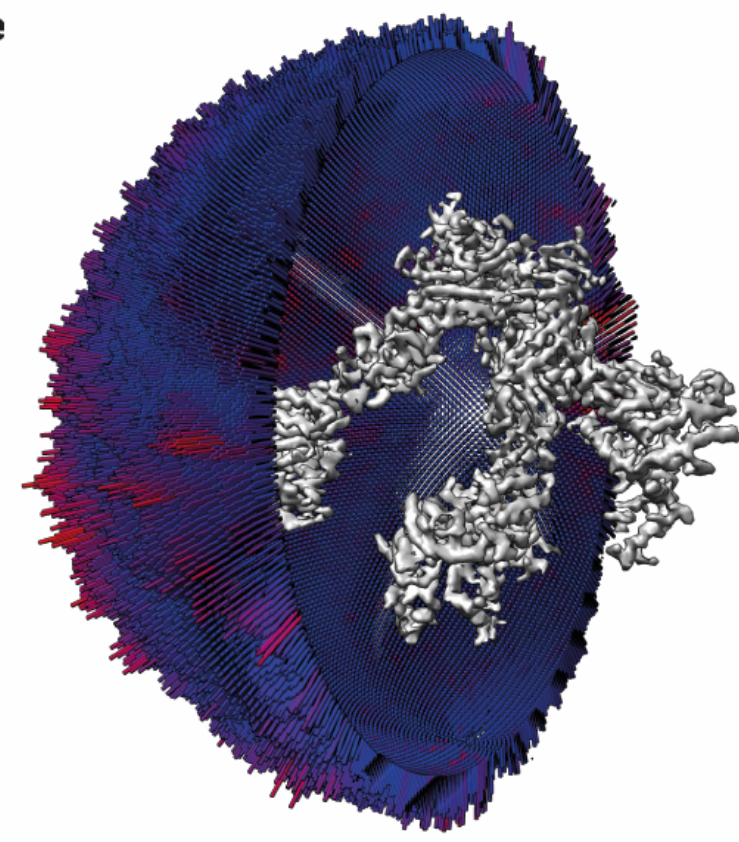

b

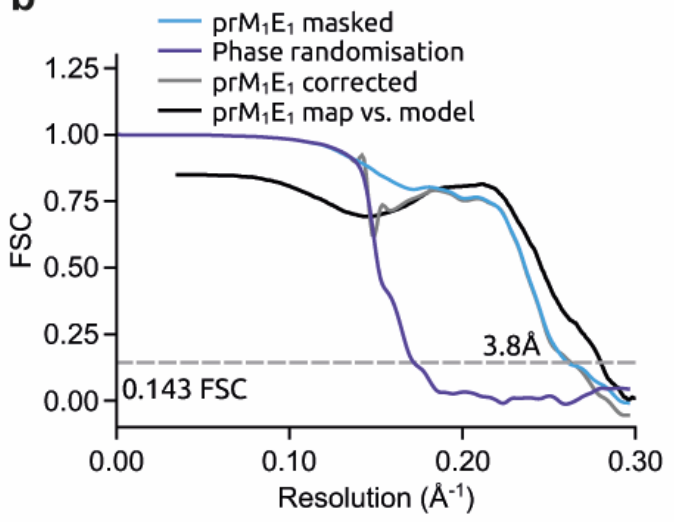

d

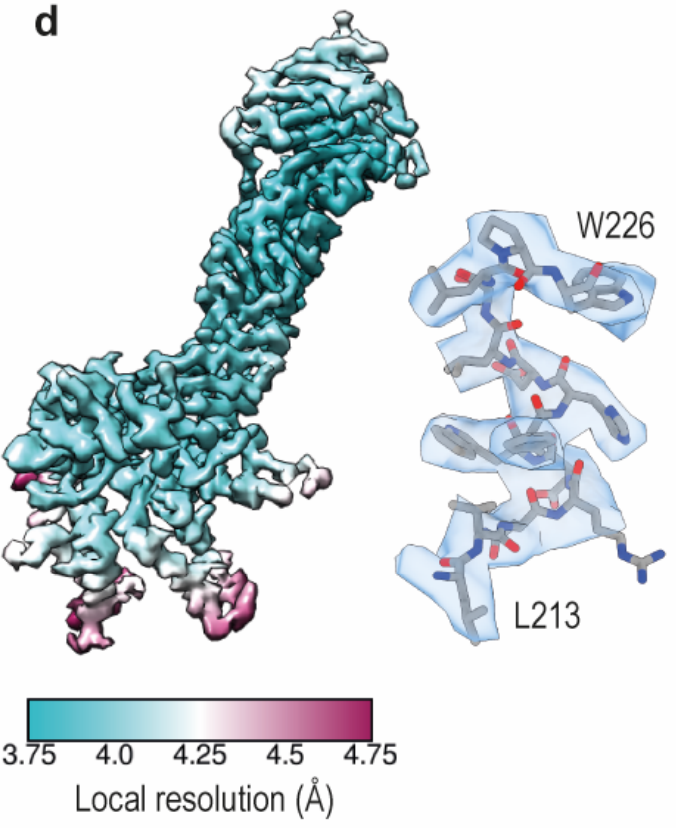

f

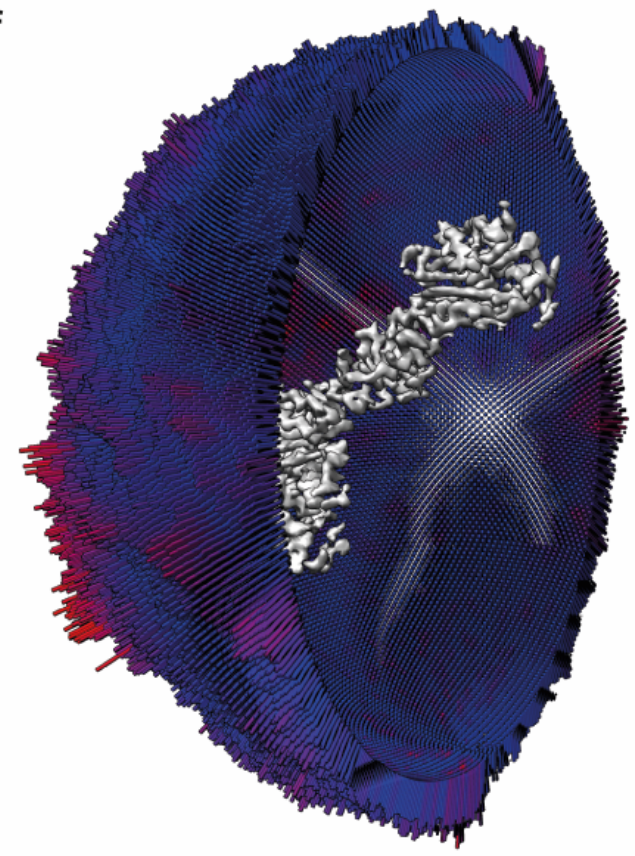


bioRxiv preprint doi: https://doi.org/10.1101/2020.06.07.138669; this version posted June 7, 2020. The copyright holder for this preprint (which was not certified by peer review) is the author/funder, who has granted bioRxiv a license to display the preprint in perpetuity. It is made available under aCC-BY-NC-ND 4.0 International license.

Extended Data Fig. 3 | Cryo-EM localized reconstruction and model refinement of immature SPOV. a, and $\mathbf{b}$, Fourier shell correlation (FSC) plots of reconstructions using gold-standard refinement in RELION for $\operatorname{prM}_{3} \mathrm{E}_{3}$ trimers and $\mathrm{prM}_{1} \mathrm{E}_{1}$ monomer, respectively. Approximate map resolutions according to the 0.143 FSC cutoff are indicated for all reconstructions. Curves are shown for masked maps, phase randomization, corrected maps, and map vs refined atomic model. c, and $\mathbf{d}$, 3D reconstructions of trimer and monomer, coloured by local resolution (according to RELION). In panel d, a representative fit of model to density is shown. e, and $\mathbf{f}$, Angular distribution of particles for the reconstructions of trimer and monomer, respectively. 

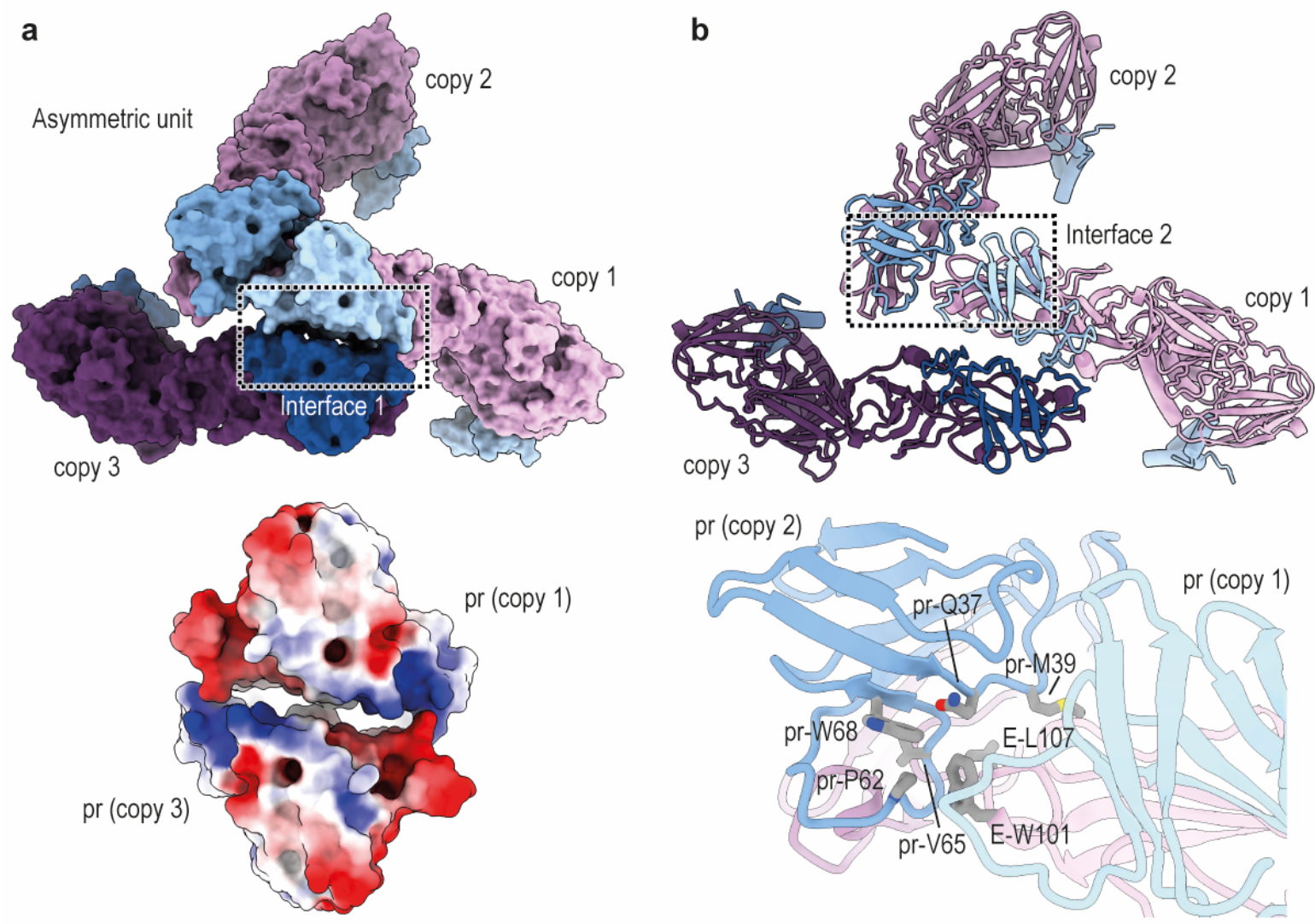

Extended Data Fig. 4 | Interaction surfaces within prM $_{3} E_{3}$ spikes. a, Topview of a prM $\mathrm{E}_{3}$ trimeric spike, shown in surface representation (prM copies are coloured in shades of blue, $E$ in shades of purple). The trimer represents the content of an icosahedral asymmetric unit of the virus. The three copies of $\operatorname{prM}_{1} \mathrm{E}_{1}$ are indicated. Intra-spike interaction is primarily mediated through the pr-domains. The bottom of the panel shows a close-up of the electrostatic surface (coloured from blue for positively charged to red for negatively charged) of the indicated interface 1 . Complementary positively and negatively charged surfaces are responsible for the interaction between pr of copy 1 and pr of copy 3. b, Topview of the trimer shown in the same orientation as in panel a, but in ribbon representation. The second major interaction interface is indicated and a close up of the interface is shown at the bottom of the panel. Interface 2 is dominated by hydrophobic contacts. Involved residues are indicated. 
bioRxiv preprint doi: https://doi org/10.1101/2020.06.07 138669; this version posted June 7, 2020. The copyright holder for this preprin (which was not certified by peer review) is the author/funder, who has granted bioRxiv a license to display the preprint in perpetuity. It is made available under aCC-BY-NC-ND 4.0 International license.
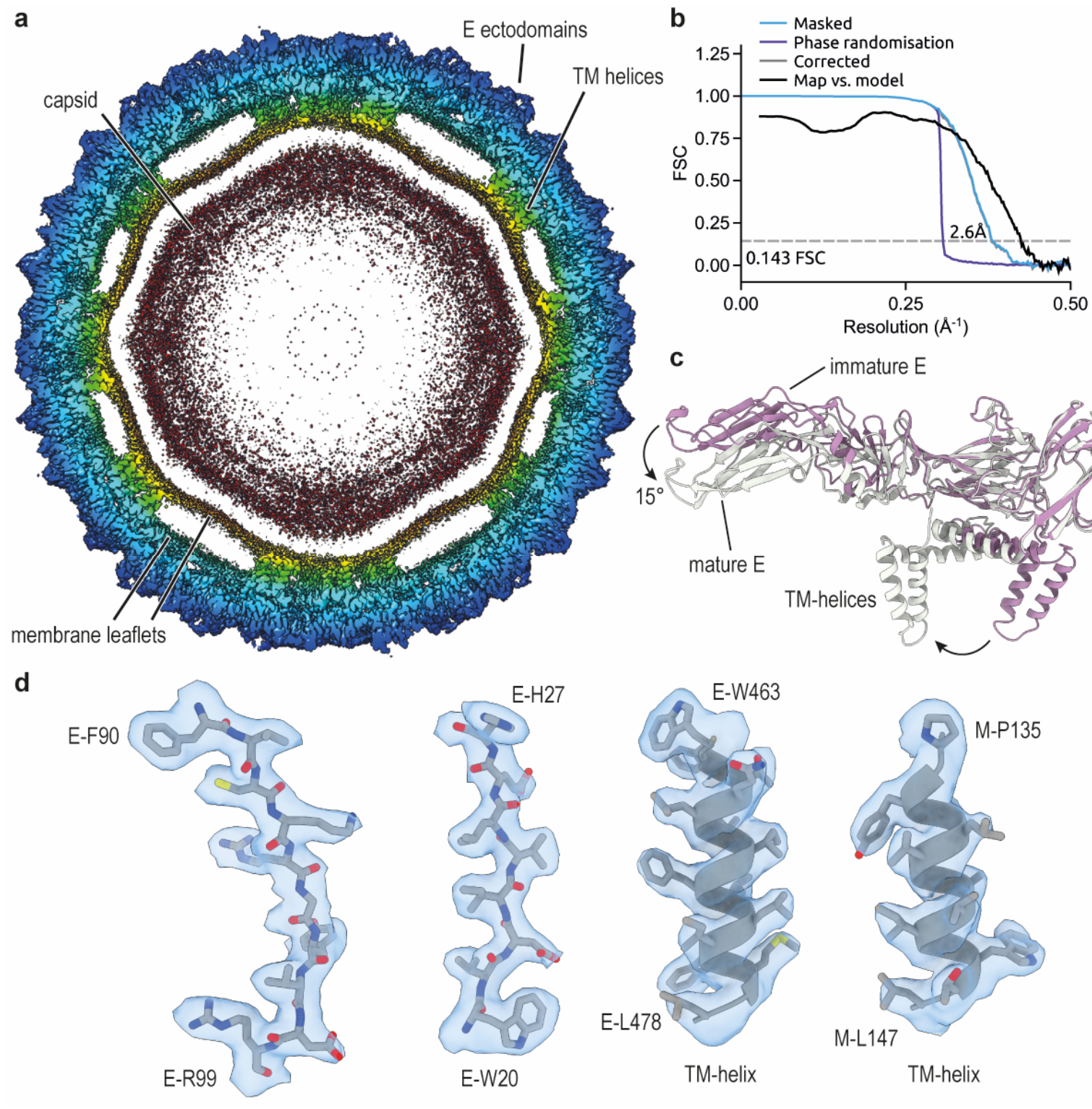

Extended Data Fig. 5 | Icosahedral cryo-EM reconstruction and model refinement of mature SPOV. a,

Slice through the cryo-EM density of the virion, coloured by radius from red to blue. $\mathbf{b}$, Fourier shell correlation (FSC) plots using gold-standard refinement in RELION. Approximate map resolution according to the $0.143 \mathrm{FSC}$ cutoff is indicated. Curves are shown for masked maps, phase randomization, corrected maps, and map vs refined atomic model. c, Hinge motion of the E protein. Aligned ectodomains of E reveal a $\sim 15^{\circ}$ hinge movement as indicated (mature $E$ in grey, immature $E$ in purple). Also of note is the repositioning of the membrane associated helices, going from immature to mature E. d, Close-ups of cryoEM density with atomic model, showcasing the quality of the map. TM-helices are also shown for $E$ and $M$. 
a

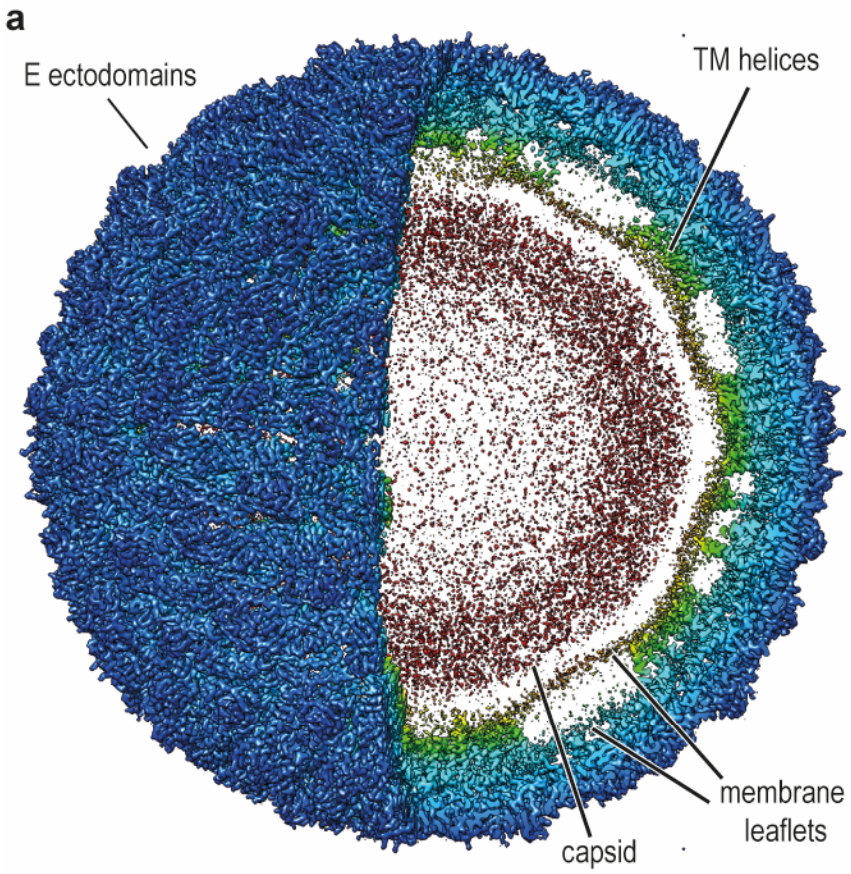

C

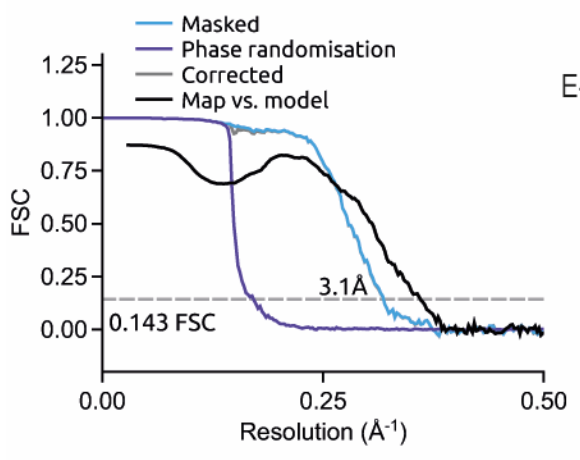

d

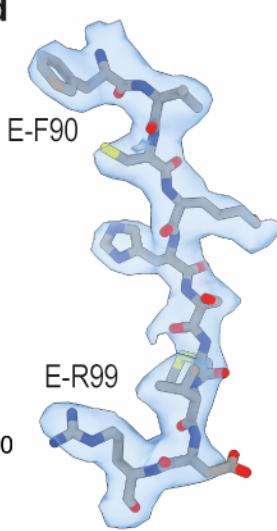

b

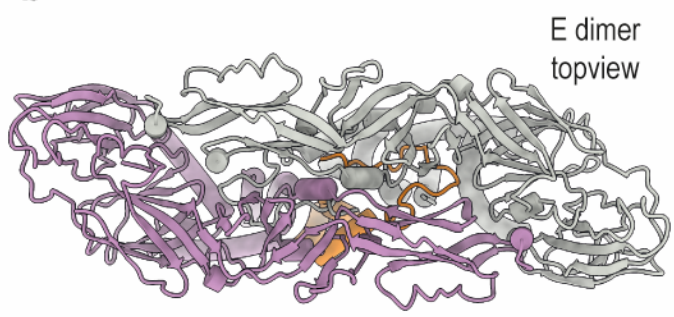

$-\left(\frac{1}{9} 90^{\circ}\right.$

E dimer sideview
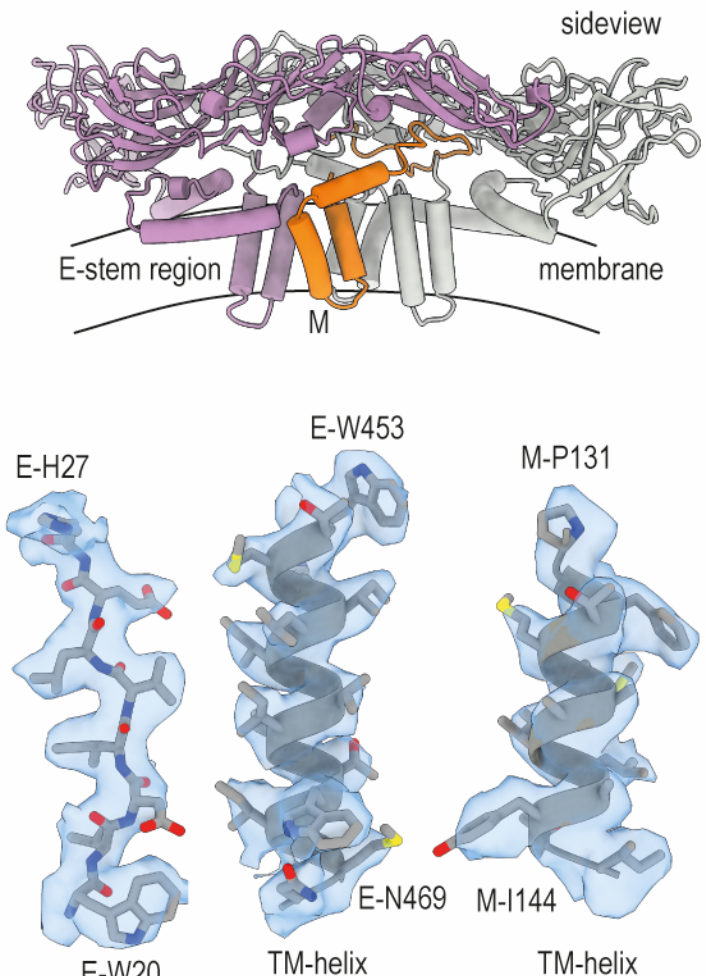

E-W20
E-W453

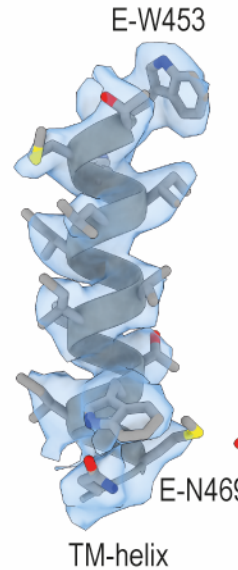

E-N
M-P131

Extended Data Fig. 6 | Icosahedral cryo-EM reconstruction and model refinement of mature DENV2. a,

Surface and sliced view of the cryo-EM density of the virion, coloured by radius from red to blue. $\mathbf{b}$, Topview and side-view of an antiparallel dimer of $E$, which compose the surface of the mature virus, in ribbon representation. The $\mathrm{M}$ protein is indicated in the side-view, as well as a schematic of the viral membrane. c, Fourier shell correlation (FSC) plots using gold-standard refinement in RELION. Approximate map resolution according to the 0.143 FSC cutoff is indicated. Curves are shown for masked maps, phase randomization, corrected maps, and map vs refined atomic model. d, Close-ups of cryo-EM density with atomic model, showcasing the quality of the map. TM-helices are also shown for $\mathrm{E}$ and $\mathrm{M}$. 
bioRxiv preprint doi: https://doi.org/10.1101/2020.06.07.138669; this version posted June $7,2020$. The copyright holder for this preprint (which was not certified by peer review) is the author/funder, who has granted bioRxiv a license to display the preprint in perpetuity. It is made available under aCC-BY-NC-ND 4.0 International license.

\begin{tabular}{|c|c|c|c|c|c|}
\hline & $\begin{array}{c}\text { Immature SPOV } \\
\text { virion } \\
\text { PDB: }\end{array}$ & $\begin{array}{c}\text { Immature SPOV } \\
\text { trimeric spike } \\
\left.\text { (prM } \mathrm{p}_{3}\right) \\
\text { PDB: }\end{array}$ & $\begin{array}{c}\text { Immature SPOV } \\
\text { heterodimer } \\
\left(p^{2} \mathrm{M}_{1} \mathrm{E}_{1}\right) \\
\text { PDB: }\end{array}$ & $\begin{array}{c}\text { Mature SPOV } \\
\text { virion } \\
\text { PDB: }\end{array}$ & $\begin{array}{c}\text { Mature DENV2 } \\
\text { virion } \\
\text { PDB: }\end{array}$ \\
\hline \multicolumn{6}{|l|}{ Data collection and processing } \\
\hline Microscope & Titan Krios & Titan Krios & Titan Krios & Titan Krios & F30 Polara \\
\hline Detector & Gatan K3 & Gatan K3 & Gatan K3 & Gatan K3 & Gatan K2 Summit \\
\hline Voltage (kV) & 300 & 300 & 300 & 300 & 300 \\
\hline Recording mode & Super resolution & Super resolution & Super resolution & Super resolution & Super resolution \\
\hline Electron exposure $\left(\mathrm{e}^{-} / \AA^{2}\right)$ & 30.00 & 30.00 & 30.00 & 30.00 & 32.00 \\
\hline Defocus Range $(\mu \mathrm{m})$ & -0.5 to -2.0 & -0.5 to -2.0 & -0.5 to -2.0 & -0.5 to -2.0 & -0.7 to -2.7 \\
\hline Magnification & 165,000 & 165,000 & 165,000 & 165,000 & 59,170 \\
\hline Movie pixel size $(\AA ̊)$ & 0.4225 & 0.4225 & 0.4225 & 0.4225 & 0.44 \\
\hline Final map pixel size $(\AA ̊)$ & 1.69 & 1.69 & 1.69 & 0.845 & 0.88 \\
\hline Symmetry imposed & 11 & $\mathrm{C} 1$ & $\mathrm{C} 1$ & 11 & 11 \\
\hline Initial particle images (no.) & 42,880 & $\begin{array}{c}2,572,800 \\
\text { subparticles }\end{array}$ & $\begin{array}{c}2,572,800 \\
\text { subparticles }\end{array}$ & 160,341 & 6676 \\
\hline Final particle images (no.) & 11,768 & $\begin{array}{c}305,017 \\
\text { subparticles }\end{array}$ & $\begin{array}{c}281,619 \\
\text { subparticles }\end{array}$ & 63,222 & 2938 \\
\hline $\begin{array}{l}\text { Map resolution } \\
\text { at } 0.143 \text { FSC threshold }(\AA)\end{array}$ & 7.8 & 4.2 & 3.8 & 2.6 & 3.1 \\
\hline Map sharpening $B$ factor $\left(\AA^{2}\right)$ & -300 & -200 & -130 & -30 & -50 \\
\hline \multicolumn{6}{|l|}{ Model Refinement } \\
\hline Initial model used (PDB code) & - & $x x x x$ (this study) & $3 c 5 x$ & $6 \cos$ & $3 \mathrm{j} 27$ \\
\hline $\begin{array}{l}\text { FSC model vs. map } \\
\text { at } 0.5 \text { threshold }(\AA)\end{array}$ & - & 4.33 & 4.07 & 2.65 & 3.27 \\
\hline CC model vs map (masked) & - & 0.75 & 0.78 & 0.89 & 0.79 \\
\hline Model composition & - & & & & \\
\hline Non-hydrogen atoms & - & 15,096 & 5,032 & 13,476 & 13,209 \\
\hline Protein residues & - & 1,965 & 655 & 1,734 & 1,698 \\
\hline Non-protein residues & - & 3 & 1 & 12 & 6 \\
\hline \multicolumn{6}{|l|}{$B$ factors $\left(\AA^{2}\right)$} \\
\hline Protein & - & 100.2 & 78.8 & 69.70 & 61.09 \\
\hline
\end{tabular}


bioRxiv preprint doi: https://doi.org/10.1101/2020.06.07.138669; this version posted June 7, 2020. The copyright holder for this preprint (which was not certified by peer review) is the author/funder, who has granted bioRxiv a license to display the preprint in perpetuity. It is made available under aCC-BY-NC-ND 4.0 International license.

\begin{tabular}{|c|c|c|c|c|c|}
\hline Non-protein & - & 152.4 & 89.0 & 92.16 & 71.91 \\
\hline \multicolumn{6}{|l|}{ R.m.s deviations } \\
\hline Bond lengths $(\AA)$ & - & 0.002 & 0.002 & 0.006 & 0.002 \\
\hline Bond angles $\left({ }^{\circ}\right)$ & - & 0.539 & 0.549 & 0.538 & 0.439 \\
\hline \multicolumn{6}{|l|}{ Validation } \\
\hline MolProbity score & - & 1.66 & 1.53 & 2.01 & 1.69 \\
\hline Clashscore & - & 6.10 & 5.73 & 5.35 & 9.61 \\
\hline Poor rotamers (\%) & - & 1.55 & 1.12 & 4.39 & 1.39 \\
\hline \multicolumn{6}{|l|}{ Ramachandran plot } \\
\hline Favored & - & 96.97 & 96.92 & 96.46 & 97.36 \\
\hline Allowed & - & 2.93 & 3.08 & 4.39 & 2.37 \\
\hline Disallowed & - & 0.10 & 0.00 & 0.00 & 0.00 \\
\hline
\end{tabular}

Extended Data Table 1 | Cryo-EM data collection, processing and model refinement statistics.

All SPOV reconstructions were carried out using a single dataset. 